\title{
HIPPOCAMPAL RHYTHMIC SLOW ACTIVITY (RSA; THETA): A CRITICAL ANALYSIS OF SELECTED STUDIES AND DISCUSSION OF POSSIBLE SPECIES-DIFFERENCES
}

\section{TERRY E. ROBINSON}

Psychology Department and Neuroscience Laboratory, The University of Michigan, Ann Arbor, Mich. 48109 (U.S.A.)

(Accepted February 5th, 1980)

Key words: hippocampal RSA - theta - arousal rhythm - RSA-generators

\section{CONTENTS}

1. Introduction . . . . . . . . . . . . . . . . . . . . . . . . . . . . . . . . . 69

2. RSA generator zones . . . . . . . . . . . . . . . . . . . . . . . . . . 70

3. Importance of electrode position . . . . . . . . . . . . . . . . . . . . . . . . . 73

4. RSA amplitude comparisons across published reports and across species . . . . . . . . 77

5. Species differences . . . . . . . . . . . . . . . . . . . . . . . . . . . . . . . 81

5.1. Rats . . . . . . . . . . . . . . . . . . . . . . . . 81

5.2. Rabbits . . . . . . . . . . . . . . . . . . . . . . . . . . . 84

5.3. Mice . . . . . . . . . . . . . . . . . . . . . . . . . . 85

5.4. Gerbils and guinca pigs . . . . . . . . . . . . . . . . . . . . . . . . . 86

5.5. Dogs . . . . . . . . . . . . . . . . . . . . . . . . 87

5.6. Cats . . . . . . . . . . . . . . . . . . . . . . . . . 87

5.7. Active (paradoxical) sleep . . . . . . . . . . . . . . . . . . . . . . . . . . . 89

5.8. Primates . . . . . . . . . . . . . . . . . . . . . . . . . . . . . . . . . . . . . . . . . . . . . 89

6. Conclusions . . . . . . . . . . . . . . . . . . . . . . . . 91

7. Summary . . . . . . . . . . . . . . . . . . . . . . . 94

Acknowledgements . . . . . . . . . . . . . . . . . . . . . 95

References . . . . . . . . . . . . . . . . . . . 95

\section{INTRODUCTION}

Green and Arduini ${ }^{67}$ first described hippocampal rhythmic slow activity (RSA; theta) as the hippocampal 'arousal rhythm', and since then numerous studies have been published relating RSA to a host of inferred processes, including arousal, attention, general motivational changes, frustrative non-reward, information pro- 
cessing, learning and memory, as well as voluntary (type 1) movements, approaching a goal and the orienting reflex $2,20,46,60,61,63,82,87,99,121,141,142$. Most of the hypotheses relating RSA to inferred processes have been critically examined in a number of recent articles $22,106,109,142,145,146,148,149$, as have those relating RSA to ongoing motor behavior $1,16,18,82,93$. The purpose of this article is not to repeat the various arguments pro and con for various theories, but to attempt to evaluate the adequacy of previous reports solely on the basis of the quality of the electrical records published. Such an evaluation is particularly pertinent at this point in time because of data which have recently become available concerning the physiological basis of hippocampal RSA (see below). These data provide information which enables one to determine reasonably well how effectively various researchers were able to tap the hippocampal generator zones for RSA.

This paper first reviews the evidence for two generators of hippocampal RSA. The implications this information has in understanding the various amplitudes and patterns of hippocampal electrical activity, which can be recorded with electrodes of different configurations, is then discussed. This information is applied in an analysis of selected studies which have related hippocampal RSA to behavior. It is shown that there is enormous variation in how well different researchers have tapped the RSA generator zones. It is suggested that the electrode placements used in some studies may have provided misinformation as to whether or not the hippocampus was in the RSA 'mode', and therefore conclusions based on these studies should be viewed with great caution.

Finally, the idea that much of the controversy concerning the correlates of RSA is due to species differences is examined ${ }^{18,161}$. The last review of species differences in the occurrence of RSA concluded that, "there is a distinct set of theta-correlated behaviors for each species'161 (p. 479). Although this statement is generally true, it needs to be modified in the light of recent evidence. It appears that in fact there are two pharmacologically distinct forms of RSA $^{89,143}$. An atropine-resistant form occurs if and only if an animal performs a type 1 ("voluntary') behavior ${ }^{143}$ (movement-related RSA; MRSA), while an atropine-sensitive form may occur during complete immobility (immobility-related RSA; IRSA). Within species which are reported to show RSA, there do not appear to be major species differences, in that all species which have been appropriately examined have the neural mechanisms necessary for producing both atropine-sensitive and atropine-resistant RSA. All of the species thoroughly studied thus far also show relations of RSA to ongoing motor behavior (MRSA). However, there are species differences in the occurrence of atropine-sensitive, IRSA. Therefore, the answer to the question as to whether there are species differences in RSA is yes, and no, depending on how specifically the question is stated or interpreted.

\section{RSA GENERATOR ZONES}

Early work suggested that there is one generator of hippocampal RSA, located in the pyramidal cell layer 68,69 . However, recent studies have indicated that in fact there are probably two independent generators of RSA in the hippocampus, which are 
approximately $180^{\circ}$ out-of-phase $25,27,30,162-165$. If the recordings are taken simultaneously from a moving microelectrode, and a fixed electrode located in stratum moleculare of the dentate (see Fig. 1), the moving electrode encounters a zone of high amplitude RSA in stratum oriens of CA1, just above the pyramidal cell layer. The maximum amplitude of RSA recorded from this 'dorsal generator' is approximately 1 $\mathrm{mV}$, and this RSA is approximately $180^{\circ}$ out-of-phase with the RSA recorded by the fixed electrode below the pyramidal cell layer. If the movable electrode is then passed through the pyramidal cell layer RSA disappears just below it (null zone). When the electrode advances further, RSA rapidly reappears but is now in phase with the RSA at the fixed electrode. The amplitude of RSA then increases steadily as the moving electrode progresses, and reaches a maximum in the outermost portion of molecular layer of the dentate granule cells ${ }^{25,30,68,162}$. If the electrode is advanced still further RSA disappears and a zone of fast activity $(30-50 \mathrm{~Hz})$ is encountered in the hilus of the dentate gyrus of rats; (in rabbits and cats RSA can be recorded throughout the hilus ${ }^{25,27}$; also see ref. 153). RSA reappears as the molecular layer of the lower blade of the dentate is reached ${ }^{30}$. The maximum amplitude of RSA produced in the lower blade of the dentate (approx. $1 \mathrm{mV}$ ) is lower than that produced in the upper blade (approx. $2 \mathrm{mV}$ ), and the amplitude of the RSA produced in stratum oriens is more variable than that produced in the dentate ${ }^{30}$. This type of profile, Winson's type $1^{164}$, is obtained in curarized rats and rabbits, urethanized cats, and in freely moving rabbits. In rabbits this type 1 profile is obtained regardless of whether RSA is recorded during spontaneous movements, in response to sensory stimulation, or during active (paradoxical) sleep. However, the profile obtained from freely moving rats differs somewhat from the above since there is no null zone and a gradual, rather than a sudden, phase reversal $162,164,165$.

Green et al. ${ }^{68}$ had concluded that RSA is produced by one generator, or dipole, located between the basal and apical dendrites of the pyramidal cells, but additional evidence supports the view of 2 independent generators discussed above. First, Winson ${ }^{162,163}$ has noted that the signals recorded with two different electrodes, both located in either the dorsal or ventral generator zones, are isomorphic, i.e. they 'have approximately the same form, waxing and waning together in time'162 (p. 292). However, the signals recorded in stratum oriens are not isomorphic with the signals recorded in the dentate. Although the signals recorded from the dorsal and ventral generator zones are phase-locked and approximately $180^{\circ}$ out-of-phase they have different wave shapes and show independent amplitude modulation. Also, Bland et al. ${ }^{25}$ reported that $\mathrm{RSA}$ in the ventral generator zone survives the disruption of RSA in the more dorsal zone, making the notion of a common generator unlikely. Whishaw et al. ${ }^{153}$ attempted to selectively destroy the dentate generator by $\mathrm{X}$-irradiating neonatal rats. However, RSA survived in both stratum oriens and in the upper blade of the dentate, although the density of granule cells was reduced by approximately $85 \%$. In the lower blade of the dentate, where granule cells were eliminated, no RSA amplitude peak was found. Even more compelling evidence for two generators comes from intracellular recording studies which have shown that both hippocampal pyramidal cells $^{13,53,58,59}$ and dentate granule cells ${ }^{7}$ show rhythmical membrane potential 


\section{REF ROVING}

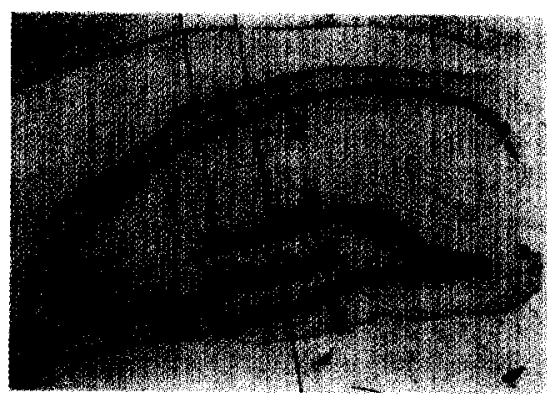

\section{REFERENCE GENERATOR SITE}

\section{ST. MOLECULARE}

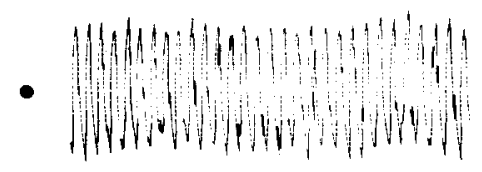

hp STIM. $(.2 \mathrm{~mA})$

PHASE FROM $X-Y$ PLOTS

\section{ROVING CAI - DENTATE TRACK}

- 1<smiles>C#CC#CC#CC#CC#C</smiles>

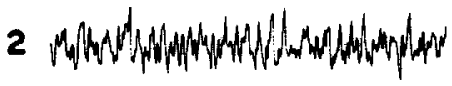

3
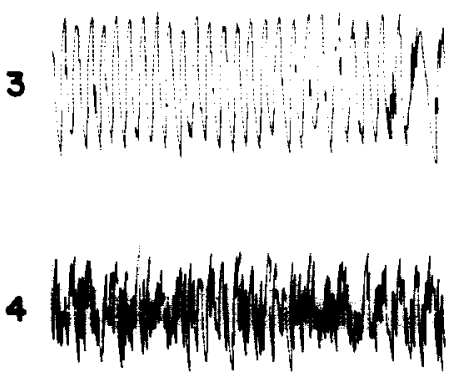

5

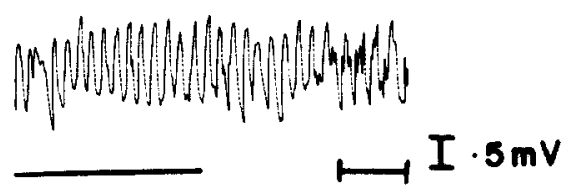

hp STIM. (.2 mA)

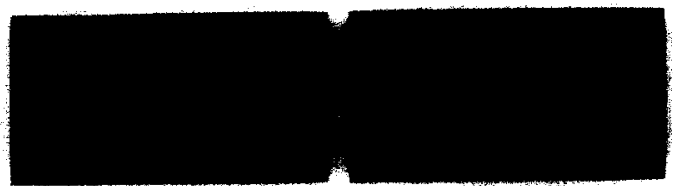

I v\& REFERENCE
3 v\& REFERENCE

Fig. 1. Distribution of hippocampal RSA in a hippocampal profile obtained during muscular paralysis. Insert in upper left corner is a photomicrograph of a sagittal section of the hippocampal formation approximately $2.5 \mathrm{~mm}$ from the midline. The reference electrode is located in stratum moleculare and the lesion is indicated diagramatically by the open circle. The penetration of the roving electrode is also indicated diagramatically and the open circle at point 1 indicates the marker lesion made in stratum oriens. Records of the activity at each numbered location correspond to the numbered records to the right of the section. 1 , stratum oriens; 2 , null zone in stratum radiatum; 3 , stratum moleculare; 4 , fast activity in hilus; 5 , stratum moleculare lower blade. The record below the section with the circle next to it represents the activity recorded from the reference electrode in stratum moleculare. Solid bars indicate the duration of the electrical stimulation $(0.2 \mathrm{~mA})$ of the posterior hypothalamus. Phase is shown by the Lissajous patterns taken from $X-Y$ plots. Left: RSA from point 1 in stratum oriens is approximately $180^{\circ}$ out of phase compared with the reference in stratum moleculare. Right: RSA from point 3 in stratum moleculare is in phase with RSA recorded from the reference electrode in stratum moleculare (Reprinted with permission from Whishaw et al. ${ }^{154}$.) 
oscillations which are synchonous with RSA. In addition, it has recently been shown that when RSA is present in the hippocampus electrophysiologically identified pyramidal cells and granule cells fire rhythmically in phase with the RSA ${ }^{8,26}$. Bland et al. ${ }^{26}$ concluded that, 'The CAl pyramidal cells and dentate granule cells appear as the main population of neurons participating in hippocampal slow wave rhythmicity, supporting the 'two generator' hypothesis of theta waves.'

Green and co-workers ${ }^{68,69}$ suggested earlier that, since maximum amplitude RSA is obtained in the dendritic layers of the hippocampus, where action potentials are rarely encountered, RSA is probably not due to envelopes of action potentials but to nonpropagated electrotonic changes in synaptic potentials. This is strongly supported by the data of Fujita and Sato ${ }^{53}$, who suggested that RSA is due to extracellular field currents driven by the 'intracellular theta rhythm.'

\section{IMPORTANCE OF ELECTRODE POSITION}

The consequences of the above findings for understanding the patterns of hippocampal electrical activity which can be recorded with gross electrodes of different configurations, placed in different areas of the hippocampus, are of the utmost importance. Perusal of Figs. 1 and 2 illustrates some of these consequences.

A very common method used to record brain slow wave activity (EEG) in freely moving animals is to place a bipolar recording electrode into the structure of interest and to connect each pole of the bipolar electrode to one input of a differential amplifier. The differential amplifier will therefore amplify the differences in electrical potential between the two poles of the electrode, but signals occurring in phase at each pole of the electrode will be attenuated. The popularity of this procedure is probably due to a considerable reduction in artifacts (e.g. movement artifacts), relative to those seen with a monopolar arrangement. Because of the laminar structure of the hippocampus and the location of the RSA generators, difference recordings obtained with electrodes of slightly different configurations yield very different patterns of electrical activity. For example, if a bipolar electrode were situated in stratum oriens such that each pole of the electrode were at the level of Position 1 on Fig. 1, and a differential recording were made, only very low amplitude RSA, or no RSA, would be recorded. This is because with an electrode positioned in this way the RSA signals at each pole of the bipolar electrode would be largely in phase and isomorphic, and the differential amplifier would reject the very signals the experimenter is trying to record. The same would be true if the bipolar electrode were situated below the pyramidal cell layer, say at Position 3 on Fig. 1. The hippocampus may actually be generating a 2000 $\mu \mathrm{V}$ signal in this region, but with a side-by-side style bipolar electrode the recorded signal may only reach $50-100 \mu \mathrm{V}$ in amplitude. This is most amply demonstrated in Fig. 2. It can be seen in Fig. 2 that when a monopolar recording was taken from stratum moleculare of the dentate, during electrical stimulation of the hypothalamus, very large amplitude RSA was recorded (Fig. 2B, C). However, when a simultaneous bipolar recording was taken with an electrode whose tips were both located in stratum moleculare, little or no RSA was apparent (note the point on Fig. 2A when both the 

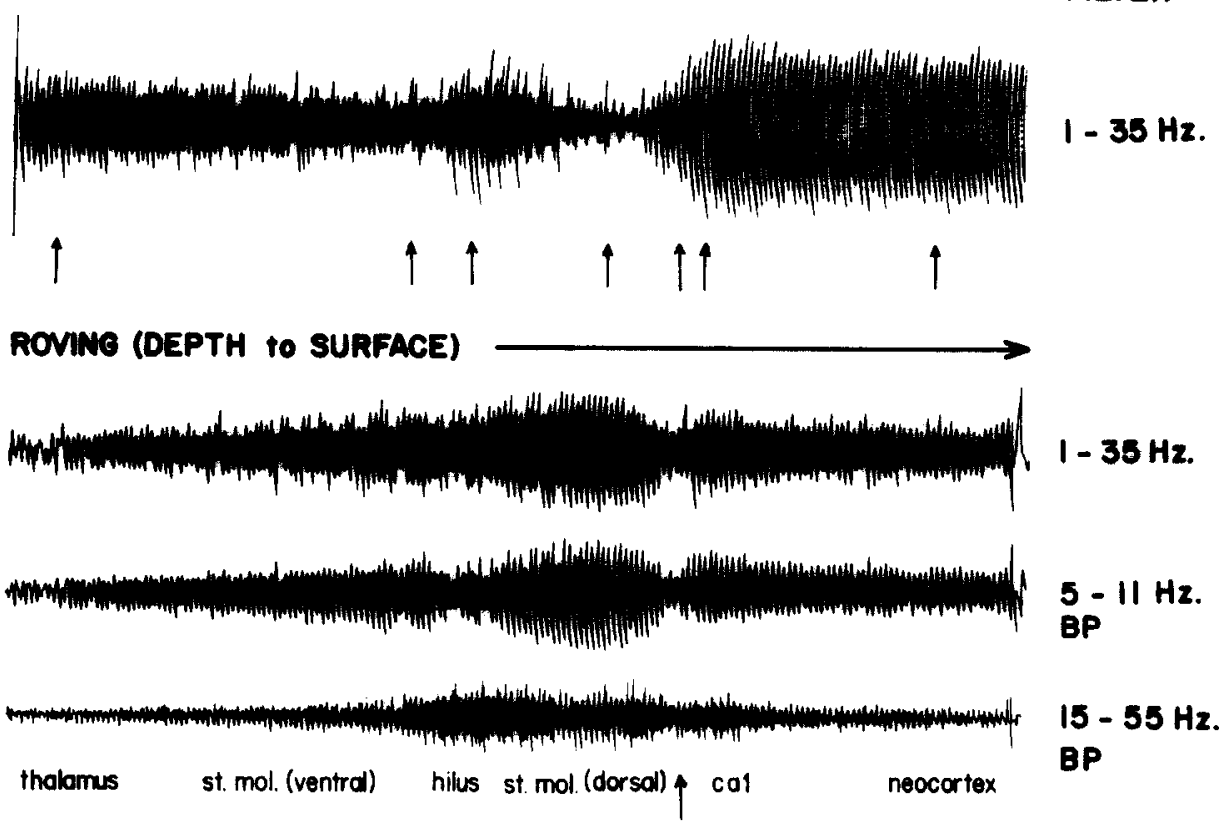

st. radiatum

\section{REFERENCE (ST. MOLECULARE)}

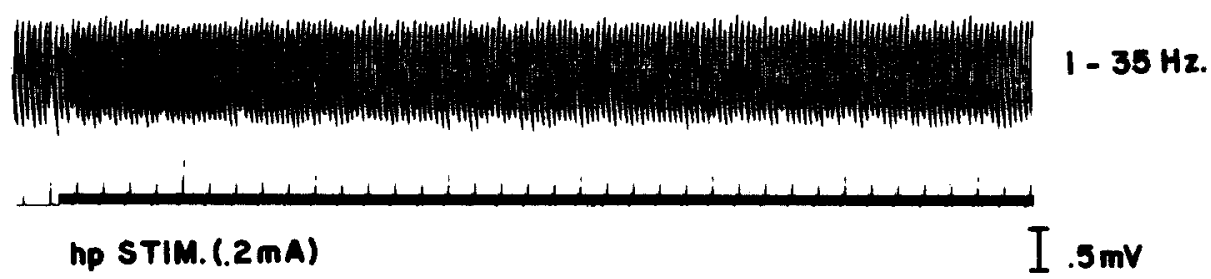

Fig. 2. Depth to surface recordings of hippocampal RSA in a CA1-dentate profile. A: a bipolar recording between the roving and reference microelectrode made as the roving microelectrode was withdrawn from the thalamus to brain surface at a constant rate. B: 3 records taken from the roving electrode only while it was being withdrawn, the activity being recorded at filter settings 1 and $35 \mathrm{~Hz}$, 5 and $11 \mathrm{~Hz}$, and $15-55 \mathrm{~Hz}$, respectively. The anatomical sites indicated along the bottom record apply to all records in A and B. C: activity recorded from the fixed electrode located in the stratum moleculare while the roving electrode was being withdrawn. The solid bar indicates both posterior hypothalamic stimulation and withdrawal of the roving electrode. (Reprinted with permission from Bland and Whishaw ${ }^{30}$.)

reference and roving electrodes are in stratum moleculare - fourth arrow from the left).

In contrast, if one pole of a bipolar electrode is situated above the pyramidal cell layer, in stratum oriens, and the other pole below the pyramidal cell layer in the outermost portion of the dentate molecular layer, and a differential recording made, RSA of an amplitude up to $2000-3000 \mu \mathrm{V}$ may be recorded. This is because the signal generated in stratum oriens is approximately $180^{\circ}$ out-of-phase from the signal 
generated in the lower generator (dentate) and the differential amplifier would add these out-of-phase signals. This phenomenon can be clearly seen in Fig. 2. When the roving electrode reached stratum oriens and a bipolar recording was made between that roving electrode and the reference electrode, which remained fixed in stratum moleculare, very large amplitude RSA was recorded (note the RSA between the two arrows furthest to the right on Fig. 2A). Therefore, depending on the exact configuration of the recording electrodes the amplitude of the signals recorded from a hippocampus, which is generating a constant signal, may vary from $0-50 \mu \mathrm{V}$ to 3000 $\mu \mathrm{V}$.

For the purposes of this paper a 'high quality' record refers to the type of signal obtained from electrodes optimally placed in the RSA generator zones described above. High quality records can be obtained with either bipolar or monopolar configurations, although it is easier with staggered bipolar electrodes. High quality records are typically of large amplitude (over $1 \mathrm{mV}$ ) and relatively devoid of fast activity ${ }^{141}$. The RSA in Figs. 1 and 2 here is considered high quality. Especially good examples of high quality records obtained simultaneously with monopolar and bipolar electrodes in freely moving rats can be seen in Fig. 5B of Whishaw et al. ${ }^{153}$. If electrodes are optimally placed in the hippocampal RSA generator zones high quality RSA can routinely be recorded from animal-to-animal and lab-to-lab.

The importance of obtaining large amplitude, high quality signals devoid of fast activity when attempting to correlate hippocampal electrical activity to behavior, or to any other variable, has been emphasized numerous times in the literature. Unfortunately, these suggestions often seem to have been ignored. In his seminal paper on the relations of hippocampal electrical activity to behavior Vanderwolf ${ }^{141}$ (p. 409) clearly stated that, 'many of the relations [to behavior] could be observed only when recording from points yielding clear large amplitude RSA with minimal admixture of fast activity' (his italics). Also included in this paper is a figure (his Fig. 4) showing unequivocal relations to behavior obtained from a recording which yielded clear RSA, while recordings taken simultaneously from the same hippocampus or contralateral hippocampus failed to show any relations to behavior. These latter sites yielded relatively low amplitude signals which contained considerable fast activity. It has also been noted that if one (or both) tip(s) of a bipolar electrode enters the hilus of the dentate in rats considerable fast activity is encountered and poor relations to behavior are seen 29,160 . The recording technique used by Vanderwolf has been described in a technical report ${ }^{42}$. There have been figures published in a number of additional papers showing the extreme variations in hippocampal electrical patterns obtained from electrodes placed in different portions of the hippocampus, and the lack of a relation of RSA to behavior with some placements ${ }^{29,80,141,143,148,160}$. The need for high quality recordings has been noted in the text of even more papers $48,89,142,151,156,159,161$.

It is especially important to have large amplitude clear signals in studies where drugs are administered. Some drugs (e.g. atropine or scopolamine) may seem to abolish hippocampal RSA at recording sites yielding low quality signals (e.g. refs. 21 and 133), while simultaneous recordings of higher quality show that in fact the drug did not abolish RSA ${ }^{143,144}$. This point has been emphasized previously by Vanderwolf 
who noted, 'Preservation of reasonably clear RSA during gross movements following atropinization could be demonstrated only at sites where the RSA, in the absence of any drug, had a large amplitude (preferably $1 \mathrm{mV}$ or more) and little admixture of fast wave activity' (ref. 143, p. 308; ref. 144, p. 194).

Some researchers may have failed to notice the relations of RSA to behavior because rather than recording RSA from electrodes placed in the hippocampus, it was recorded from electrodes placed in the neocortex (e.g. refs. 92, 94-96). These neocortical placements yielded only very low amplitude RSA, on the order of $150-200$ $\mu V$ (see Table I). Landfield ${ }^{92,94}$ has argued that this 'neocortical RSA' is not volumeconducted from the hippocampus, but neurally conducted. A recent study by Gerbrandt et al. ${ }^{54}$ suggests that, in fact, neocortical RSA is probably volumeconducted from the hippocampus. The amplitude of neocortical RSA is highest directly over the dorsal hippocampus; there are no regions of RSA amplitude minima or maxima found upon laminar profiles through the neocortex, RSA amplitude peaks are found in the hippocampus itself (see above), and unilateral cortical spreading depression is relatively ineffective in suppressing neocortical RSA. In addition, extrahippocampal RSA has been reported to show similar relations to behavior as hippocampal RSA, and septal lesions abolish both hippocampal and extrahippocampal RSA $^{67,75,97}$ (also see ref. 166). For these reasons it is most likely that RSA originates in the hippocampus and is volume-conducted to distant structures $25,30,54,111,162$.

Even if neocortical RSA were of neocortical origin, Landfield seems to have used it as an indicator of hippocampal activity. 'The important factor is that cortical theta is very highly correlated with hippocampal theta, and therefore cortical records provide a reliable index of activation of the hippocampal rhythm' ${ }^{\prime 4}$ (p. 440). This is even though Landfield ${ }^{92}$ (p. 10) reported, 'that cortical. . theta rhythms spontaneously or experimentally disappear while hippocampal rhythms continue', which would in itself indicate that neocortically recorded RSA is not a good indicator of hippocampal activity. The conclusion warranted here is that studies in which hippocampal RSA was recorded from electrodes placed in sites distant from the hippocampus, such as the neocortex, are especially suspect in terms of providing information as to hippocampal function.

In conclusion, the above studies make it patently clear that the results obtained from one lab or in one study may differ from those obtained in other labs or studies no: necessarily because of real differences in the behavioral or psychological processes revealed by the different experimental designs, but simply because of differences in the quality of the records obtained. It is also clear that some electrode placements and/or configurations may result in recordings which are extremely misleading, as they may indicate that the hippocampus is not in the RSA (theta) 'mode' when in fact it is. This may lead to gross misinterpretations as to just what hippocampal electrical activity is related to. In light of these facts it seems highly appropriate to examine the various studies which have led to controversies as to the correlate(s) of hippocampal RSA, and to evaluate the published EEG records. 


\section{RSA AMPLITUDE COMPARISONS ACROSS PUBLISHED REPORTS AND ACROSS SPECIES}

In an attempt to gain information as to how successful previous researchers have been in placing their recording electrodes to take advantage of the unique laminar structure and location of the RSA generators in the hippocampus, I have measured the maximum amplitude of RSA shown in published reports. This was done by using a clear plastic ruler to measure the peak-to-peak amplitude (in $\mathrm{mm}$ ) of the largest single RSA wave seen in a train of RSA waves which lasted at least $1 \mathrm{sec}$. The size of the signal was then converted to $\mu \mathrm{V}$ by using the calibration signal provided (if it were provided). Measures were taken from all the available figures in any one paper but only the largest RSA amplitude found recorded. This approach entails two assumptions. (1) It is assumed that the published records are indicative of at least the average quality of recordings obtained in the study in question. In fact, this is probably a very

TABLE I

Maximum published amplitude of hippocampal RSA-Rats

\begin{tabular}{|c|c|c|c|c|c|}
\hline Rank & $\begin{array}{l}\text { Max. } \\
\text { amplitude } \\
(\mu V)\end{array}$ & Reference & Rank & $\begin{array}{l}\text { Max. } \\
\text { amplitude } \\
(\mu V)\end{array}$ & Reference \\
\hline 1 & 2666 & Whishaw et al. ${ }^{153}$ & 19 & 750 & Vanderwolf 141 \\
\hline 2 & 2400 & Vanderwolf ${ }^{143}$ & 20 & 714 & Gray et al. ${ }^{66}$ \\
\hline 3 & 2250 & Whishaw et al. ${ }^{157}$ & 21 & 643 & Gray $^{64}$ \\
\hline \multirow[t]{2}{*}{3} & 2250 & Whishaw and & & & \\
\hline & & Vanderwolf ${ }^{160}$ & 22 & 625 & Frederickson et al. 49 \\
\hline \multirow[t]{2}{*}{4} & 2000 & Robinson and & & & \\
\hline & & Vanderwolf ${ }^{116}$ & 23 & 600 & Irmis et al. ${ }^{78}$ \\
\hline 4 & 2000 & Bland and Whishaw ${ }^{30}$ & 24 & 571 & Teitelbaum et al. ${ }^{133}$ \\
\hline 5 & 1875 & Bland and Vanderwolf ${ }^{28}$ & 25 & 533 & Sano et al. ${ }^{125}$ \\
\hline 6 & 1833 & Vanderwolf et al. ${ }^{149}$ & 26 & 500 & Komisaruk $^{86}$ \\
\hline 7 & 1600 & Whishaw and Schallert ${ }^{158}$ & 27 & 489 & Urban and De Wied ${ }^{139}$ \\
\hline 7 & 1600 & Whishaw et al. 154 & 28 & 429 & Kurtz and Adler ${ }^{91}$ \\
\hline 8 & 1571 & Vanderwolf et al. ${ }^{148}$ & 29 & 333 & Kurtz ${ }^{90}$ \\
\hline 9 & 1500 & Vanderwolf and Cooley ${ }^{14 ?}$ & 29 & 333 & Irmis et al. ${ }^{79}$ \\
\hline 10 & 1425 & DeRyck and Teitelbaum ${ }^{45}$ & 30 & 240 & Routtenberg and Taub ${ }^{122}$ \\
\hline 11 & 1400 & Robinson et al. ${ }^{115}$ & 30 & 240 & McGowan-Sass ${ }^{102}$ \\
\hline 12 & 1375 & Whishaw et al. ${ }^{155}$ & 31 & 200 & Routtenberg ${ }^{120}$ \\
\hline 13 & 1250 & Robinson et al. ${ }^{117}$ & 31 & 200 & Bennett et al ${ }^{18}$ \\
\hline 13 & 1250 & H. Teitelbaumet al. ${ }^{135}$ & 32 & 164 & Landfield and McGaugh \\
\hline 14 & 1200 & \multicolumn{3}{|l|}{ Whishaw and Vanderwolf 159} & (ref. 95 ) \\
\hline \multirow[t]{2}{*}{15} & 1168 & Frederickson and & 33 & 127 & Landfield ${ }^{94}$ \\
\hline & & Whishaw ${ }^{51}$ & 34 & 118 & Routtenberg and \\
\hline \multirow[t]{2}{*}{16} & 1000 & Pickenhain and & & & Kramis $^{121}$ \\
\hline & & Klingberg ${ }^{112}$ & 35 & 117 & Urban and De Wied ${ }^{138}$ \\
\hline 16 & 1000 & Gray $^{63}$ & & & \\
\hline 16 & 1000 & Gray and Ball & & & \\
\hline 17 & 889 & Young ${ }^{168}$ & & & \\
\hline $\begin{array}{l}18 \\
19\end{array}$ & $\begin{array}{l}800 \\
750\end{array}$ & Teitelbaum and McFarland & & & \\
\hline 19 & 750 & Whishawios & & & \\
\hline
\end{tabular}


TABLE II

Maximum published amplitude of hippocampal RSA - Cats

\begin{tabular}{|c|c|c|}
\hline Rank & $\begin{array}{l}\text { Max. } \\
\text { amplitude } \\
(\mu V)\end{array}$ & Reference \\
\hline 1 & 1667 & Bland et al. ${ }^{27}$ \\
\hline 2 & 850 & Whishaw and Vanderwolf ${ }^{160}$ \\
\hline 3 & 762 & Frederickson et al. ${ }^{50}$ \\
\hline 4 & 685 & Bennett et al. ${ }^{21}$ \\
\hline 5 & 667 & Bennett et al..$^{20}$ \\
\hline 6 & 600 & Kemp and Kaada ${ }^{82}$ \\
\hline 6 & 600 & Grastyan et al. ${ }^{60}$ \\
\hline 7 & 500 & Adey et al. ${ }^{5}$ \\
\hline 7 & 500 & Brown and Shryne ${ }^{36}$ \\
\hline 8 & 475 & Elazar and Adey ${ }^{46}$ \\
\hline 9 & 457 & Bennett $^{14}$ \\
\hline 10 & 450 & Grastyan and Vereczkei ${ }^{62}$ \\
\hline 11 & 400 & Grastyan et al. ${ }^{61}$ \\
\hline 11 & 400 & Anchel and Lindsley ${ }^{6}$ \\
\hline 11 & 400 & Bennett $^{16}$ \\
\hline 11 & 400 & Sakai et al. ${ }^{124}$ \\
\hline 12 & 320 & Bemet $t^{15}$ \\
\hline 13 & 313 & Brown ${ }^{35}$ \\
\hline 14 & 250 & Bennett and French ${ }^{17}$. \\
\hline 14 & 250 & Lena and Parmeggiani ${ }^{98}$ \\
\hline 15 & 229 & Bennet and Gottfried ${ }^{19}$ \\
\hline 16 & 200 & Macadar et al. ${ }^{101}$ \\
\hline 17 & 187 & Adey and Dunlop" \\
\hline 18 & 100 & Radulovacki and Adey ${ }^{113}$ \\
\hline 18 & 100 & Adey et al. ${ }^{3}$ \\
\hline $\begin{array}{l}19 \\
20\end{array}$ & $\begin{array}{l}80 \\
55\end{array}$ & Coleman and Lindsley ${ }^{4 i}$ \\
\hline 20 & 55 & Coleman and Lindsley ${ }^{41}$ \\
\hline
\end{tabular}

conservative assumption since it is likely that published records represent better than average examples. (2) A more serious assumption is that a measure of RSA amplitude is a valid measure of the quality of the record. It is true that although a large amplitude is required to have a 'high quality' recording, more than that is required. It was stressed above that not only was a large amplitude signal required to observe clear relations of RSA to behavior, but that the signal should also have a, 'minimal admixture of fast activity'141 (p. 409). However, since it is now known what amplitudes of RSA are produced by each generator in various situations (see above), a measure of amplitude gives a good indication of how well these generators were tapped in any particular study. If the maximum RSA amplitudes reported are on the order of $50-500 \mu \mathrm{V}$ it is very likely that the electrodes were either some distance from the generator, and therefore only volume-conducted activity was recorded (see ref. 30 ), or both were in the same generator zone, and therefore the signals were largely rejected by a differential amplifier (if bipolar recordings were made). A final reason for measuring the maximum amplitude of published records is that this is relatively easy to quantify, while the amount of fast activity present is not. 
The major findings can be seen in Tables I and II and in Fig. 3. The first thing that is very obvious is that there is considerable variation in the amplitude of RSA reported in various studies, both within species and across species. In cats, the maximum published amplitudes range from a low of $55 \mu \mathrm{V}^{41}$ to a high of $1667 \mu \mathrm{V}$, which is 30.3 times higher than the lowest amplitude ${ }^{27}$. The Bland et al. ${ }^{27}$ paper is not a behavioral study but a RSA profile mapping study demonstrating the location of the RSA generators in cats. The $1667 \mu \mathrm{V}$ record published by Bland et al. ${ }^{27}$ was obtained with a bipolar electrode configuration; however, the same figure (his Fig. 4) shows

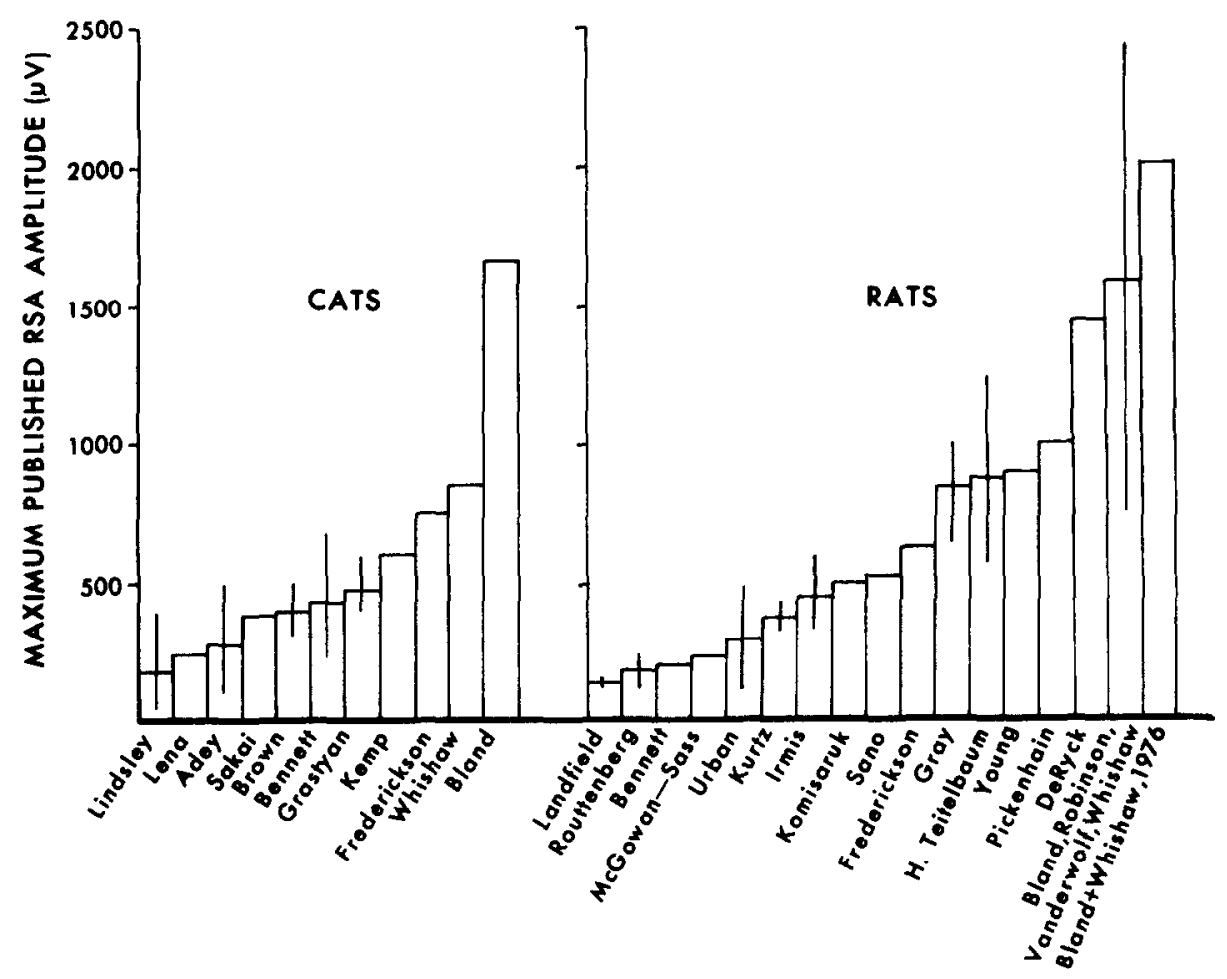

Fig. 3. Maximum published hippocampal RSA amplitudes plotted across various 'research groups'. The bars represent either the maximum published amplitude found in a single paper (in which case there is no line through the bar), or the mean maximum amplitude calculated from two or more papers. In the latter cases the lines represent the range of maximum RSA amplitudes found in the different papers sampled. RSA amplitudes found in studies with cats are to the left, and those from studies with rats to the right. The name chosen to represent a 'research group' is either the name of the first author of an individual paper or the name which consistently appeared on a series of papers. The publications and individual RSA amplitudes which contribute to Fig. 3 are found in Tables I and II. The papers sampled in each 'research group' above are as follows (from left to right): Lindsley $6.40,41,101$; Lena ${ }^{98}$; Adey $^{2,3,5,46,113}$; Sakai ${ }^{124}$; Brown ${ }^{35,36}$; Bennett ${ }^{14-17,19-21}$; Grastyan ${ }^{60-62}$; Kemp ${ }^{82}$; Frederickson ${ }^{50}$; Whishaw ${ }^{160}$; Bland ${ }^{27}$ (note that Bland et al. ${ }^{27}$ is a profile mapping study); Landfield ${ }^{94,95}$; Routtenberg $^{120-122}$; Bennett ${ }^{18}$; McGowan-Sass ${ }^{102}$; Urban ${ }^{138,139}$; Kurtz ${ }^{90,91}$; Irmis ${ }^{78,79}$; Komisaruk ${ }^{86}$; Sano $^{125}$; Fredericksor ${ }^{49}$; Gray ${ }^{63-66}$; H. Teitelbaum ${ }^{133-135}$; Young ${ }^{168}$; Pickenhain ${ }^{12}$; DeRyck ${ }^{45}$; this next column represents papers in which at least one of B. H. Bland, T. E. Robinson, C. H. Vanderwolf or I. Q. Whishaw is an author, and is referred to as the 'Vanderwolf group' in the text ${ }^{28,51,115-11 \text {, }}$ $141,143,1471140,151,154,155,157-160$; the last column represents the maximum amplitude reported by Bland and Whishaw ${ }^{30}$ in a profile mapping study. 
$1500 \mu \mathrm{V}$ RSA obtained with a monopolar electrode. Obviously high quality RSA can be obtained in cats with either technique. The behavioral study in cats with the highest reported RSA amplitude is Whishaw and Vanderwolf ${ }^{160}(850 \mu \mathrm{V})$.

In studies with rats, the lowest published RSA amplitude found was $117 \mu \mathrm{V}$, in a paper by Urban and De Wied ${ }^{138}$, and studies by Routtenberg ${ }^{120,121}$ and by Landfield ${ }^{94,95}$ reported maximum amplitudes of $200 \mu \mathrm{V}$ or less (Table I). Whishaw et al, ${ }^{1.53}$ reported the highest maximum RSA amplitude in freely moving rats (2666 $\mu \mathrm{V})$, which was 22.8 times higher than the lowest. Fig. 3 shows that some research groups consistently published reports with relatively low amplitudes while others published reports with relatively high amplitudes.

The data reported in Tables I and II were also analyzed to determine if there is a significant trend for more recent papers to contain larger amplitude RSA than papers published earlier. In fact, for rats there is a weak (although statistically significant) correlation between reported maximum amplitude RSA and year of publication ( $r=$ $+0.37, P<0.05$ ). For cat studies there is no significant correlation between reported RSA amplitude and year of publication (ref. 27 omitted from analysis, $r=+0.19 ; 27$ included in analysis, $r=+0.35$ ). This suggests that the information gained from studies on the RSA generator zones $25,27,30,162,165$ has not yet been disseminated sufficiently.

Due to the factors discussed above the variations in RSA amplitude can probably be accounted for largely by variations in the electrode configurations used by different groups. In reviewing the literature I attempted to determine just what kind of recording techniques and electrode configurations were used in various studies, but gave up because that information was so often missing from individual reports. This information should always be included to facilitate comparisons across studies.

Other information missing from a number of reports was a figure illustrating original EEG records (e.g. refs. 4, 31, 39, 47, 57, 77 and 137). (Needless to say, such studies were by necessity omitted from this analysis.) These papers usually presented the results of spectral analyses or other automated statistical treatments of the original EEG data. This makes interpretation of these studies very difficult because one needs to know the quality of the raw data to intelligently interpret the statistical treatment of it. Although, when used proparly, the various methods available for quantifying EEG data may increase the accuracy and precision of data analysis, no type of spectral analysis, or other method of analyzing EEG data, will compensate for low quality original records.

The data in Fig. 3 are also very interesting in regards to the many processes RSA has been correlated with in various studies. It is evident that those studies which related hippocampal RSA to ongoing motor behavior (largely the "Vanderwolf group': Bland, Robinson, Vanderwolf, Whishaw) all fall at the high end of the amplitude scale. In cats, the studies which related the occurrence of RSA to behaviors such as walking (Type I) contained published records showing the two highest RSA amplitudes found $(762 \mu \mathrm{V})^{50}$ and $(850 \mu \mathrm{V})^{160}$. Those studies relating the occurrence of RSA to inferred processes, such as attention, arousal, orienting or learning and memory (e.g. Adey, Bennett, Grastyan, Lindsley) all published records of considerably 
lower amplitude. However, it is important to note that even the amplitude reported by Whishaw and Vanderwolf ${ }^{160}$ is only approximately one-half of the maximum published amplitude $(1667 \mu \mathrm{V})^{27}$. Theoretically, when differential recordings are made across the out-of-phase generators amplitudes up to $3000 \mu \mathrm{V}$ should be possible ${ }^{27}$, depending on behavioral state. The lack of studies in cats which report maximum RSA amplitudes comparable to those reported in rats ${ }^{143}$ suggests that behavioral studies in cats with optimally placed electrodes remain to be done.

The above trend is even more obvious in studies with rats. The maximum RSA amplitudes reported by the 'Vanderwolf group' are much higher than those reported by most others. After the mean 'Vanderwolf group' maximum RSA amplitude the next highest was reported by DeRyck and Teitelbaum ${ }^{45}$, the next by Pickenhain and Klingberg ${ }^{112}$ and the next by Young ${ }^{168}$. The maximum RSA amplitude reported by Pickenhain and Klingberg 112 was in their Fig. 8, which illustrates very clear relations of RSA to behavior. The other two studies 45,168 essentially confirmed (and then extended) the original observations of Vanderwolf ${ }^{141}$. There is no overlap between the lowest maximum RSA amplitude reported by the 'Vanderwolf group' for rats and the maximum RSA amplitudes for rats reported by 10 of the other research groups shown in Fig. 3. These differences are exaggerated if comparisons are made between studies on cats versus rats. There is no overlap between the lowest maximum RSA amplitude reported by the 'Vanderwolf group' for rats and any of the studies on cats which related hippocampal RSA to inferred process, such as arousal, attention or learning and memory. The largest RSA amplitude reported in a behavioral study with rats was $2666 \mu \mathrm{V}^{153}$ and this approaches the theoretical maximum of $3000 \mu \mathrm{V}$ suggested by Bland and Whishaw 30 . Indeed, the $2666 \mu \mathrm{V}$ RSA reported by Whishaw et al. ${ }^{153}$ is of greater amplitude than the maximum amplitude of bipolar records published by Bland and Whishaw ${ }^{30}$ in their profile mapping study (Fig. 3). This suggests that behavioral studies in rats with optimally placed electrodes have been done, but with a few exceptions (e.g. ref. 45), done mainly by the 'Vanderwolf group'.

It is implied above that cats are really not much different from rats in terms of the relations of hippocampal RSA to behavior. Those studies in cats which reported relatively large amplitude RSA, related RSA to behaviors that it has been related to in rats. However, cats are not exactly like rats in terms of hippocampal electrical activity, and the concept of species differences has been evoked to account for many of the controversies over the correlates of RSA ${ }^{21,161}$. Clearly, the discussion above suggests that other factors, such as comparisons between studies with low versus high amplitude hippocampal slow wave records may account for many of the discrepancies. In this regard it would be beneficial at this point to determine just how and to what extent the species studied thus far do differ in terms of hippocampal RSA.

\section{SPECIES DIFFERENCES}

\subsection{Rats}

There is general agreement that in most (but not all) situations the occurrence of 
hippocampal RSA is invariably accompanied by the performance of certain behaviors in freely moving rats $22,28,39,45,106,109,114,116,128,141,148,150,155,159-161,168$. That is, whenever a rat produces a behavior such as walking, rearing, head movements or swimming (type 1 or 'voluntary' movements ${ }^{141,143}$ ) these behaviors are accompanied by hippocampal RSA (movement RSA: MRSA). However, whenever a rat is immobile, or when it performs a type 2 ('automatic', more reflexive) behavior such as licking, chewing, shivering or grooming, these behaviors are not accompanied by RSA, but by large amplitude irregular activity (LIA). In normal undrugged and otherwise unmanipulated rats the correlation between the occurrence of RSA and of a type 1 behavior is very strong, and has been confirmed at the level of single unit analysis $108,114,150$. It should be noted once again that the correlation is strong only if high quality records are obtained.

On the other hand, there are situations in which rats may produce RSA in the absence of any observable motor activity (immobility RSA : IRSA). For example, after posterior-lateral hypothalamic lesions $45,85,118$ or after treatment with various drugs (e.g. reserpine, ether, urethane) rats may show long trains of RSA during immobility ${ }^{149}$. After training in a situation where a tone is followed by inescapable footshock IRSA may appear in the interval between tone and the footshock, without the occurrence of type 1 movements ${ }^{151}$. An obvious exception to the rule that RSA is accompanied by type 1 movements is the occurrence of IRSA during active (paradoxical; REM) sleep. Lastly, electrical stimulation of the brain stem reticular formation may produce hippocampal RSA in the absence of any movements ${ }^{116}$.

Although electrically recorded MRSA and IRSA superficially appear very similar, further research has shown that there are a number of factors which distinguish MRSA from IRSA. One immediately obvious difference (other than the difference in behavioral relations) is that in most (but not all) situations MRSA has a higher frequency than IRSA. For example, electrical stimulation of various brain stem sites produced 5.4-6.9 Hz IRSA but stimulation-induced MRSA varied from 8.0 to 9.1 $\mathrm{Hz}^{116}$. The mean frequency of RSA accompanying walking is $8.0 \mathrm{~Hz}^{141}$, while the mean frequency of RSA seen under ether anesthesia is $5.0 \mathrm{~Hz}^{143}$ (range $4.5-5.8 \mathrm{~Hz}$ ). During active sleep the frequency of MRSA accompanying phasic muscular twitches varies from an average of 7.5 to $8.6 \mathrm{~Hz}$, while the frequency of IRSA which occurs during the tonic immobility of active sleep ranges from 6.4 to $7.3 \mathrm{~Hz}^{115}$ (also see refs. 131 and 160 ).

The major distinction which has been made between MRSA and IRSA is pharmacological, i.e. they are differentially affected by, and can be doubly dissociated with, various drugs ${ }^{89,143,149,152}$. In all of those situations discussed above in which IRSA appears, that IRSA can be abolished by a systemic injection of atropine sulfate (25-50 mg/kg i.p., $5 \mathrm{mg} / \mathrm{kg}$ i.v.), i.e. IRSA is usually atropine-sensitive. Conversely, the RSA which accompanies type 1 behaviors (MRSA) is not abolished by atropine sulfate, i.e. MRSA is usually atropine-resistant. The reverse is seen with volatile anesthetics, such as ether. Rats anesthetized with ether will show long trains of IRSA and this IRSA is atropine-sensitive. Therefore, ether-resistant RSA is atropinesensitive. However, if an atropinized rat (which has atropine-resistant, movement- 
related RSA intact) is given ether, both atropine-resistant RSA and type 1 behaviors are abolished. Therefore atropine-resistant RSA is ether-sensitive. In sum, IRSA is usually atropine-sensitive and ether-resistant while MRSA is usually atropine-resistant and ether-sensitive. In addition, various other drugs can dissociate atropine-resistant and atropine-sensitive RSA (see refs. 149 and 152).

A common criticism of the experiments with atropine is that very large systemic doses are required to abolish what is termed atropine-sensitive RSA. The reason large doses of atropine are required probably has to do with the low lipid solubility of atropine ${ }^{34,74}$. After a systemic injection of atropine high concentrations of the drug are found in peripheral tissues, such as the heart, but the concentration in the brain is much lower ${ }^{136}$. It is unlikely the effects of atropine on hippocampal electrical activity are due to a non-specific depressant or toxic effect, rather than to its competitive inhibition of acetylcholine. Atropine-sensitive RSA is not abolished by central nervous system depressants, such as ether or alcohol ${ }^{89,152}$, although atropine-resistant RSA is abolished by these agents. In addition, increases in the dosage of atropine from 25 to $100 \mathrm{mg} / \mathrm{kg}$ have no further effect on hippocampal electrical activity, and doses as high as $150 \mathrm{mg} / \mathrm{kg}$ (i.p.) do not abolish atropine-resistant movement-related RSA ${ }^{143}$. Also, if atropine had a non-specific depressant effect it would be expected to have a more pronounced effect on RSA which has a relatively high threshold to electrical stimulation of the reticular formation. In fact, just the opposite is found. Stimulation of various brain stem sites elicits immobility-related RSA at lower current intensities than movement-related (atropine-resistant) RSA, but immobility-related RSA is nevertheless selectively sensitive to atropine ${ }^{116}$. The effects of atropine on cerebral electrical activity are not due to the peripheral effects of the drug either, since in large doses the quaternary ammonium derivative atropine methyl nitrate, which does not cross the blood-brain barrier, has no effect on cerebral activation ${ }^{143}$.

Additional evidence supporting the anticholinergic effect of atropine outlined above comes from studies in which cholinergic systems have been manipulated in other ways. Intraventricular injections of hemicholinium-3 (HC-3) deplete brain acetylcholine $(\mathrm{ACh})$, presumably by competing with choline for a $\mathrm{Na}^{+}$-dependent high affinity uptake mechanism at cholinergic terminals ${ }^{70,119}$. In recent unpublished experiments (D. J. Green and T. E. Robinson, 1980) we have found that intraventricular HC-3 abolishes the IRSA produced by electrical stimulation of the reticular formation in urethanized rats (this IRSA is atropine-sensitive), but does not abolish the movement-related RSA which accompanies spontaneous walking (this MRSA is atropine-resistant). A systemic injection of choline chloride restores the occurrence of electrical stimulation-induced IRSA in urethanized, $\mathrm{HC}-3$ treated rats.

The above observations have led to the concept that there are at least two inputs to the hippocampus of rats, each of which is capable of producing RSA, but which are at some point pharmacologically distinct (see refs. 89, 143, 145, 148 and 149 for reviews). An atropine-resistant input produces $\mathrm{RSA}$ if, and only if, a type 1 behavior occurs and this atropine-resistant RSA is usually of a relatively high frequency (7-12 $\mathrm{Hz}$ ), and is ether-sensitive. An atropine-sensitive input may produce RSA during 
behavioral immobility, but does not invariably do so, and this atropine-sensitive RSA is usually of a relatively low frequency $(<7 \mathrm{~Hz})$, and is ether-resistant. It should be noted that these two systems are operationally defined on the basis of their relative sensitivity to drugs, but not on their relations to behavior or frequency spectra. This is because atropine-resistant RSA may on occasion be induced during immobility, for example in curarized rats ${ }^{154}$, and the frequency ranges may overlap considerably in some situations.

The finding that there are two types of RSA raises the question as to whether the two generators of RSA are neurochemically distinct, i.e. is one form of RSA generated by one of the two hippocampal RSA generators and the other form by the other generator? If this were true it is possible that the two generators may not always be simultaneously active, and may be differentially affected by drugs. In such a situation bipolar recordings across the generators may be misleading since one generator could be abolished without clear evidence of this in the record (other than through a loss of amplitude). However, it appears that both the stratum oriens and dentate generators produce both atropine-resistant and atropine-sensitive forms of RSA ${ }^{153,154}$. Microelectrodes placed in the 'dorsal' and 'ventral' generators both continue to record RSA during type 1 behaviors following atropine treatment, and RSA during immobility following urethane or eserine. All RSA is abolished at both generators by a combination of atropine and urethane. To date no one has reported being able to uncouple the two generators, and in all of the situations examined thus far, when one is active so is the other ${ }^{30,153,154}$. If the two generators are always simultaneously active then staggered bipolar electrodes provide the easiest means of tapping the generators. However, if as yet unknown functional differences do exist between the two generators then these may be overlooked by the use of bipolar recordings. Obviously, the best strategy would be to simultaneously take monopolar records from both the CAI and dentate generators, and a difference recording between the two generators.

Given that rats show clear relations of RSA to behavior (MRSA), on occasion show RSA during immobility (IRSA), and have both atropine-resistant and atropinesensitive forms of RSA, it is of interest to us here to determine whether other species show a similar pattern.

\subsection{Rabhits}

The most extensive study on lagomorphs relating hippocampal electrical activity to behavior, and the one with the largest published maximum amplitude RSA (1668 $\mu \mathrm{V}$ ), is by Kramis et al. ${ }^{89}$. Kramis et al. ${ }^{89}$ reported that, like rats, rabbits produce RSA whenever a type 1 behavior occurs (e.g. hopping, running, rearing), but usually show no RSA during undisturbed but 'alert' immobility. However, as reported earlier by Harper ${ }^{72}$, Kramis et al. ${ }^{89}$ noted that rabbits differ from rats in that on many occasions they may produce clear RSA during complete behavioral immobility. 'Such theta (RSA) activity could be elicited by any type of peripheral sensory stimulus, including flashes of light, tones, buzzers, whistles, movement of a nearby rabbit and experimenter movement. . ' ${ }^{\prime 89}$ (p. 65 ; also see refs. $72,83,84$ and 148). As in rats, MRSA in 
rabbits usually has a higher frequency than IRSA $72,89,152$. The frequency of RSA accompanying hopping ranges from 7.4 to $8.5 \mathrm{~Hz}$, while that of RSA elicited by sensory stimulation in the absence of movement is from 6.3 to $7.5 \mathrm{~Hz}^{89}$.

Studies which have examined the effects of drugs such as atropine and ether on hippocampal RSA in rabbits have reported effects very similar to those found in rats $^{89,152,157}$. In rabbits the RSA which occurs during behavioral immobility (IRSA) or in association with type 2 movements is abolished by systemic injections of atropine sulfate, but is not abolished by ether or alcohol anesthesia. Conversely, the MRSA associated with type 1 behaviors is atropine-resistant, but ether-sensitive. Whishaw ${ }^{152}$ reported that atropine-resistant MRSA is also sensitive to (abolished by) anesthetic doses of ethyl alcohol. In addition, the two types of RSA are also distinguished by different rates of ontogenetic development in rabbits. In neonatal rabbits atropineresistant MRSA develops approximately one week earlier than sensory or eserineinduced atropine-sensitive IRSA ${ }^{56,148}$ (also B. H. Bland, personal communication).

It seems, therefore, that both rats and rabbits have an atropine-resistant form of RSA which accompanies type 1 movements, is of relatively high frequency, and is ether-sensitive. Both rats and rabbits also have an atropine-sensitive form of RSA which may occur during behavioral immobility (but does not invariably do so), is of relatively low frequency, and is ether-resistant. Where the rat and rabbit differ is in the probability of the atropine-sensitive system becoming activated. In normal unmanipulated rats, atropine-sensitive IRSA is essentially never seen, while it is quite common in rabbits, especially during sensory stimulation. Therefore, the information available to date would indicate that these two species do not differ in that both have neural systems capable of producing both forms of RSA, but do differ in that the neural system(s) reponsible for producing atropine-sensitive IRSA is much more easily activated in rabbits.

\subsection{Mice}

Very recently the relations of hippocampal electrical activity to behavior have been examined in both heterozygous $(\mathrm{Pa} /+)$ black mice and homozygous $(\mathrm{Pa} / \mathrm{Pa})$ pallid mice (Jackson C57BL/6 strain) by Frederickson et al.48. These researchers found that, as in rats and rabbits, the occurrence of hippocampal RSA in both strains of mice is tightly correlated with ongoing motor behavior. Whenever mice produced a type 1 behavior (e.g. walking, rearing, climbing) that behavior was accompanied by $7-12 \mathrm{~Hz}$ hippocampal RSA, while during immobility or type 2 behaviors (e.g. licking, chewing, face-washing) large amplitude irregular activity (LIA) dominated the hippocampal record. As often seen in rabbits, and on occasion in rats, a mouse sometimes produced a brief train of low frequ. acy IRSA (4-7 Hz), especially if it 'froze' by the experimenter's hand. Therefore, in freely moving undrugged mice the relations of hippocampal electrical activity to behavior look very similar, if not identical, to that seen in rats ${ }^{48}$.

Further experiments with cholinergic agonists and antagonists revealed that, like rats and rabbits, mice are capable of producing both atropine-sensitive and atropine- 
resistant forms of $\mathrm{RSA}^{48}$. After an injection of eserine (an anticholinesterase) mice produce long continuous trains of RSA during behavioral immobility, as previously reported in rats ${ }^{143}$ and rabbits ${ }^{37}$, and this IRSA is abolished by atropine (i.e. it is atropine-sensitive). However, after an injection of atropine mice continue to show atropine-resistant MRSA in association with type 1 movements.

Finally, it should be noted that Frederickson et al. ${ }^{48}$ found that the maximum amplitude of RSA varied from mouse to mouse and that this variation was related to electrode position. Those hippocampal placements nearest the outermost portion of the molecular layer of the dentate produced the largest amplitude RSA (maximum reported RSA amplitude $=1429 \mu \mathrm{V}$ ), while placements deviating from this site produced considerably smaller amplitude RSA.

\subsection{Gerbils and guinea pigs}

The relations of hippocampal electrical activity to behavior described for gerbils $^{8,151}$ and guinea pigs ${ }^{123}$ are very similar to those described previously for rats, rabbits and mice (see above). Whishaw ${ }^{151}$ (p. 233) reported that in gerbils, 'RSA occurs during... movements such as running, swimming, rearing, jumping, and walking, while more automatic movements such as grooming, chewing food, lapping water or simply alert immobility are associated with LIA.' Kramis and Routtenberg88 also observed that foot-stomping, a species-specific behavior which occurs during mating behaviors, is not accompanied by RSA, although active exploratory behaviors are. In addition, the details of the hippocampal RSA waveform, amplitude and frequency, are related to the same behavioral details in gerbils as reported in rats ${ }^{151}$. The largest published maximum amplitude RSA reported for gerbils (1778 $\mu \mathrm{V})$ was found in Whishaw ${ }^{151}$. Profile studies of the RSA generators have not been done in gerbils, but if they are similar to species in which profiles have been done the amplitudes reported by Whishaw ${ }^{151}$ suggest that the electrode placements in this study tapped the generators quite effectively.

Guinea pigs do not provide an exception to the correlation between hippocampal RSA and behavior outlined thus far for other species. As in the above species guinea pigs with appropriately placed electrodes (maximum published amplitude = $1285 \mu \mathrm{V}^{123}$ ) consistently show RSA during the performance of type 1 behaviors but not during undisturbed immobility or type 2 behaviors ${ }^{123}$. However, guinea pigs do differ from rats, and are more like rabbits, in that sensory stimuli may elicit short trains of low frequency IRSA (T. E. Robinson, unpublished observations).

What is lacking in the literature to allow further comparisons between rats, rabbits and mice on the one hand, and gerbils and guinea pigs on the other, are studies on the effects of cholinergic agonists and antagonists in gerbils and guinea pigs. If these latter two species are like the former three then movement-related RSA (MRSA) should survive treatment with atropine and IRSA should be abolished by atropine. Until appropriate pharmacological studies show otherwise it would seem most parsimonious to assume that they are not different, but all have both atropine-resistant and atropine-sensitive forms of RSA, especially since the relations of RSA to behavior 
are so similar across all five species. Therefore, where they probably do differ is not in terms of the neural mechanisms responsible for producing atropine-sensitive or atropine-resistant RSA, but in the probability of the atropine-sensitive system becoming active.

\subsection{Dogs}

Most of the information on the relations of hippocampal electrical activity to behavior in dogs comes from one of two labs: a Dutch lab ${ }^{9-12,81,100,132}$, or a Canadian one (that of the late A. H. Black ${ }^{22-24,44}$ ). The reports from these labs are consistent with the behavioral relations of RSA discussed thus far for other species (also see ref. 167). For example, if dogs are operantly conditioned to produce type 1 movements to one discriminative stimulus and refrain from movement to another, RSA accompanies the conditioned mobility but not the conditioned immobility22,23,44.

The most complete analysis of the relations of hippocampal electrical activity to behavior in dogs was recently published by Arnolds et al. ${ }^{9-11}$ as three back-to-back papers. In these studies hippocampal EEG was analyzed using computer-assisted spectral analysis. These authors reported a 'close relationship between modulations of the dog's hippocampal EEG activity and elementary motor acts' $(p$. 567). Clear large amplitude RSA accompanied behaviors such as walking and head movements, and transitions from one behavior to another were accompanied by RSA frequency shifts. The amplitude of RSA was found to increase as speed of walking increased, and there was a weak relationship between RSA frequency and walking speed. Passive displacement of an animal did not produce changes in the hippocampal record. Spectral analysis revealed that some activity in the theta range accompanied eating or drinking (as in the rabbit), and a few observations of IRSA in response to a familiar sound were noted.

The studies of Arnolds et al. ${ }^{9-11}$ support the contention that the occurrence of RSA is closely correlated with overt motor activity, although they point out that the behaviors accompanied by RSA are not best described by the term 'voluntary'. The description of the situations in which RSA appear in dogs sounds very similar to those for other species. Unfortunately, there are no pharmacological studies in dogs which would provide information as to whether MRSA is atropine-resistant and IRSA atropine-sensitive.

\subsection{Cats}

The comparison which usually evokes claims of species-differences, and may account for many of the controversies in the literature, is that between rats and cats ${ }^{161}$. The question which still requires critical examination, however, is whether the available data support the idea of real differences between cats and the other species discussed thus far.

The behavioral study in cats which contained the largest published maximum amplitude RSA $(850 \mu \mathrm{V})$ was by Whishaw and Vanderwolf ${ }^{160}$ and these authors 
reported many similarities in the relations of RSA to behavior in cats and rats. 'Hippocampal RSA was recorded when cats walked, made orienting movements or moved their heads, but was absent during lapping milk and chewing cat food. ${ }^{160}$. In this study two cats were forced to walk continuously for $8 \mathrm{~h}$ on a motor-driven treadmill and, 'RSA was continuously present during walking throughout the entire session, although RSA frequency was about $2-2.5 \mathrm{~Hz}$ slower than in rats' ${ }^{\prime 60}$ (p. 468 ). Whishaw and Vanderwolf ${ }^{160}$ (p. 467) also reported some differences between cats and rats in that cats had more fast activity mixed in with RSA, and in cats, 'RSA could occur. . during fixed staring (such as when a cat observes the movement of the polygraph paper, or movement outside the window)', in the absence of overt movements. Another difference between cats and rats is that in rats maximum amplitude RSA usually occurs during the performance of large type 1 movements, while the amplitude of RSA accompanying motor activity in cats is more variable. In fact, the amplitude of RSA during walking in cats may often be small relative to that which occurs during fixed staring $35,50,82$. On the other hand, the frequency of RSA in cats shows similar relations to behavior as in the other species discussed thus far, i.e. the frequency of MRSA is higher than that of IRSA. For example, Frederickson et al. ${ }^{50}$ (p. 561) reported that, ' $\mathrm{RSA}$ frequency is typically faster during locomotion (5-6 $\mathrm{Hz}$ ) than during skeletal immobility $(4-5 \mathrm{~Hz})$ in cats'.

However, disagreement has arisen because some earlier researchers have reported that RSA sometimes disappears during walking in cats (e.g. ret. 19). The discrepancy between these latter reports and the findings of Whishaw and Vanderwolf ${ }^{160}$, Frederickson et al. ${ }^{50}$ and C. Wilson (personal communication, cited in Frederickson et al. ${ }^{50}$ ), who report continuous RSA during steady walking, may be partly due to differences in the amplitude of the electrical recordings. Fig. 3 shows that most of the earlier studies on cats contained published EEG records with very low amplitude RSA. If the amplitude of RSA is already low during walking in cats, it is not surprising that RSA may be masked by the more high frequency activity seen in these low amplitude records.

In sum, cats consistently produce relatively high frequency RSA during behaviors such as walking or head movements, and in this respect do not differ from any of the species discussed thus far. However, cats may often produce relatively low frequency RSA during immobility, and in this respect are similar to rabbits and guinea pigs, but differ from rats. Again, where the species seem to differ is in the occurrence of IRSA, but not MRSA.

The more crucial question at this point is whether cats have both atropineresistant and atropine-sensitive forms of RSA, but unfortunately there are very few behavioral studies available which address this question. There is evidence available from studies on acute preparations which suggest that cats have the atropine-sensitive form of RSA. Injections of an anticholinesterase (e.g. eserine) produce long continuous trains of relatively low frequency hippocampal RSA, and this eserine-induced RSA is abolished by a subsequent injection of atropine sulfate $27,32,110$. The studies available to date on the effects of atropine on hippocampal electrical activity in freely moving cats are consistent with the notion of two pharmacologically distinct forms of 
RSA, but are not completely conclusive. Smylie et al. ${ }^{130}$ have reported in an abstract that atropine or scopolamine totally abolish the IRSA which usually accompanies immobile waiting and food lapping in their cats. Atropine does not totally abolish the RSA which accompanies walking, even though MRSA was usually of lower amplitude than IRSA. After atropine, RSA failed to accompany all walking episodes, and this is very similar to the results obtained in atropinized rats or rabbits with less than optimal electrode placements ${ }^{89,143}$. Similar results have been reported by Nakahara et al. ${ }^{107}$, who found that atropine abolished IRSA, but not MRSA in cats. Since Smylie et al. ${ }^{130}$ reported RSA amplitudes of only $350-650 \mu \mathrm{V}$ and Nakahara et al. ${ }^{107}$ only $750 \mu \mathrm{V}$ RSA, it is possible that with bipolar electrodes more optimally placed across the generators, RSA would more consistently accompany steady walking in atropinized cats, as it does in atropinized rats and rabbits. However, a firm conclusion awaits the publication of a study with optimally placed electrodes. It would be interesting if cats do prove to be substantially different from other species in regards to hippocampal activity, as it may provide a clue to the functional significance of RSA.

\subsection{Active (paradoxical) sleep}

The occurrence of hippocampal RSA during active sleep provides additional evidence for a lack of species differences. Winson ${ }^{161}$ (p. 486) noted earlier that, "there is one behavior, paradoxical sleep, that is characterized by regular, high amplitude theta activity in all species.' The relations of RSA frequency to behavior are also similar during both active sleep and waking. RSA frequency is higher during periods of phasic muscular twitches and/or rapid eye movements than during tonic immobility in active sleep in rabbits ${ }^{72}$, cats 82,124 and rats $115,125,131,160$. Also, hippocampal RSA can be pharmacologically subdivided into atropine-resistant and atropine-sensitive components in active sleep. In rats, the relatively high frequency RSA which accompanies the phasic muscular twitches during active sleep is not abolished by atropine sulphate, while the relatively low frequency RSA accompanying tonic immobility is atropinesensitive ${ }^{115}$. Similar results have been reported by Japanese researchers in both rats ${ }^{140}$ and cats ${ }^{107}$. In these latter studies eye movements were monitored and it was found that atropine abolished RSA during immobility but not during periods of vigorous rapid eye movements in active sleep.

'Thus, during both sleep and waking the atropine-resistant system is active only during movements (e.g. twitches during active sleep, and walking, running, etc. during waking). Atropine-sensitive RSA. . , on the other hand, occurs during immobility in the waking animal and during the non-twitch portions of active sleep'115 (p. 548), and this is true in the two species (cats and rats) examined thus far.

\subsection{Primates}

In contrast to the similarities in hippocampal electrical activity seen in the nonprimate species discussed above, primates stand alone. Most studies of hippocampal electrical activity in non-human primates do not report changes that are all com- 
parable to those seen in other species $43,52,67,105$. Even when spectral analyses of the EEG yield activity in the 'theta' range it is not clear, and there is no a priori reason to assume, that this activity bears any anatomical or physiological relation to the RSA recorded from the hippocampus of other species. The apparent lack of primate RSA may be related to the loss of the dorsal hippocampus in primates.

However, a few studies have reported RSA-like waves in non-human primates. For example, a figure published by $\operatorname{Heath}^{73}$ (p. 18, his Fig. 2) shows what looks like RSA in the hippocampal record from a feral-raised monkey, but the behavioral relations are uncertain. Crowne and $\operatorname{Radcliffe}^{43}$ (p. 196) have reported that RSA, "is a regularly occurring feature of the electrical activity of the hippocampus' in the monkey, but they were unable to define a reliable situation in which it appears.

Reports on human hippocampal electrical activity are also mixed. Halgren et al. ${ }^{71}$ (p. 781) recently reported, "that the human hippocampal EEG desynchronized during behaviors homologous to those accompanied by hippocampal RSA in animals.' These researchers failed to find RSA in any of the situations studied. In contrast, Sano et al. ${ }^{126}$ reported that electrical stimulation of the posterior hypothalamus in humans produces hippocampal RSA (and neocortical desynchrony), which is exactly what posterior hypothalamic stimulation produces in rats. RSA-like activity has also been recorded from an electrode located near the mid-hippocampus pes during active sleep, but only in one patient ${ }^{55}$.

The negative evidence above suggests that indeed there are species differences in hippocampal activity, at least between primates and non-primates. However, this may be too premature a conclusion, especially in the light of recent attempts to relate hippocampal function in non-humans and humans (e.g. ref. 109). Before concluding that primates do not have RSA, laminar profile analyses of the hippocampal region similar to those done in rats, rabbits and cats ${ }^{25,27,162}$ should be performed. It is possible that monkeys and humans do produce hippocampal RSA, but no one has ever placed their electrodes in the appropriate position to record it. For example, Crowne and Radcliffe ${ }^{43}$ placed their electrodes to straddle the $\mathrm{CA}_{3}$ pyramidal cell field in monkeys, but it has been reported that in rabbits and rats the $\mathrm{CA}_{3}$ region does not produce $\mathrm{RSA}^{25,30}$. These researchers also reported that in monkeys, 'Generally the larger the amplitude of the activity from an electrode, the greater is the likelihood that it will show RSA and a strong driven response from stimulation of the medial septal nucleus'43 (p. 191). In the case of humans the patterns recorded from the hippocampus are reported to vary considerably with electrode position. From her experience with humans, $\operatorname{Brazier}^{33}$ (p. 311 ) has commented, 'An aspect of this work which needs much further research concerns the exact placement of electrodes... In the hippocampus one pair of electrodes may record wave trains with completely independent characteristics from another pair only a short distance away.'

In conclusion, it is probably wise to defer strong arguments for, or against, species differences in hippocampal electrical activity between prinlates and nonprimates, at least until the data from appropriate laminar profile analyses are in. However, at present there are no data from primates showing behavioral relations of hippocampal activity that are anything like that in the other species discussed above. 


\section{CONCLUSIONS}

The literature concerning the correlates of hippocampal RSA has seen a wealth of hypotheses generated from seemingly contradictory data. It is suggested here that one of the major reasons for the contradictory data is that different researchers have varied enormously in how successful they were in tapping the RSA generator zones of the hippocampus. Only recently has it been suggested that there are two independent $180^{\circ}$ out-of-phase RSA generators, one located above the pyramidal cell layer in stratum oriens, and the other in the outermost portion of the molecular layer of the dentate 25,162 . However, the RSA phase reversal seen above and below the pyramidal cell layer has been known for some time ${ }^{68}$. Because of the location and nature of these generators, electrodes of different configurations placed in the hippocampus may yield very disparate signals. It has been amply demonstrated in numerous studies that to see clear relations of RSA to behavior the large amplitude high quality signals obtained with optimal placement of electrodes in the RSA generator zones are required. Failure to optimally place electrodes in the generator zones results in signals which may provide misinformation, since such signals may indicate the hippocampus is not in the RSA 'mode', when in fact it is. Conclusions drawn on the basis of studies with low amplitude hippocampal records with considerable fast activity must be viewed with great caution. Complex spectral analyses of the records in such studies will not compensate for the fact that the electrodes were probably inappropriately placed in the the hippocampus.

It has been suggested previously that much of the controversy over the correlates of RSA may be due to species differences ${ }^{161}$. Therefore, this idea was examined taking into account the problems of different electrode positions discussed above. It is true that if RSA is considered a unitary phenomenon, there is not a single set of behavioral correlates which is consistent across species. However, the situation is not that simple since different neural systems are probably involved in producing RSA in different behavioral states. Therefore, to answer the question as to whether there are species differences in the neural mechanisms underlying RSA, one must pose that question in a more specific manner.

In all of the species appropriately examined thus far (rats, rabbits, and mice) there appears to be two pharmacologically distinct forms of hippocampal RSA ${ }^{48,89}$, 149. One type of RSA occurs if, and only if, the animal performs a behavior such as walking, rearing or jumping (type 1 behavior), but is usually not present during behavioral immobility or the performance of behaviors such as licking, chewing, or grooming (type 2 behaviors). This type of RSA usually has relatively high frequency, develops relatively early ontogenetically (in rabbits), is not abolished by systemic injections of atropine sulfate (is atropine-resistant), but is abolished by anesthetic doses of volatile anesthetics such as ether (is ether-sensitive). The other form of RSA has different relations to behavior than atropine-resistant, movement-related RSA since it may be present during complete behavioral immobility or type 2 behaviors, although it is not invariably so. This second form of RSA has a relatively low frequency, develops relatively late (in rabbits), is atropine-sensitive, but etherresistant. 
With the exception of primates, there do not seem to be major species differences in that all of the species appropriately examined thus far have neural systems for producing both types of RSA. In addition, all of the species show clear relations of RSA to type 1 behaviors. Therefore, there probably are not major species differences in the neural systems underlying atropine-resistant, movement-related RSA. However, there are definitely species differences in the neural system(s) reponsible for producing atropine-sensitive, immobility-related RSA. Although some species (e.g. rat) are capable of producing atropine-sensitive RSA (as shown with various manipulations). they only very rarely generate it spontaneously. Other species (e.g. rabbits and cats) very commonly produce atropine-sensitive RSA during behavioral immobility, rabbits especially during sensory stimulation and cats during fixed staring. These differences in the probability of occurrence of atropine-sensitive RSA, and in the different situations it appears across species, may very well be related to differences in the behavioral strategies various species have adapted to their particular environment. Further research on both similarities and differences in hippocampal electrical activity across species may very well yield valuable information as to the evolution of hippocampal function.

At first glance the finding of two types of RSA may suggest to some that the researchers relating RSA to movement were looking at atropine-resistant RSA, and those relating it to inferred processes, such as arousal or attention, were looking at atropine-sensitive RSA, and therefore both groups were in a sense correct. Although this may be true there is very little evidence to support a claim that atropine-sensitive IRSA is related to arousal or attention.

The atropine-sensitive type of RSA is most amenable to suggestions of relations to arousal or attention because of the situations in which it appears in freely moving animals (e.g. during sensory stimulation in rabbits or fixed staring, 'attentive behavior', in cats). However, these situations are usually defined as being attentive or aroused states on the basis of relatively anthropomorphic inferences. In my opinion the most thorough studies which examined the question as to whether hippocampal RSA is related to inferred processes are those by A. H. Black and his colleagues ${ }^{22}$. These investigators conducted a series of clever experiments in dogs, cats and rats in which they attempted to hold variables such as motivation, attention and learning constant, while varying the animal's motor activity. Conversely, other experiments held motor activity constant while varying motivation, attention or learning. They found that RSA did vary as overt motor activity varied, but manipulations of motivation, attention or learning had little or no effect on hippocampal electrical activity. In their experiments in dogs, Arnolds et al. ${ }^{9}$ also raised the problem with studies which have related RSA to "higher processes like learning and information processing ${ }^{46,96}$. The experimental conditions employed in these studies. . appear to involve always changing motor behaviors as the learning of a task proceeds. To our knowledge no experiments have been carried out in which careful measurements of overt behavior showed this to be constant while at the same time the EEG showed changes in relation to the acquisition or performance of the task.' (p. 566).

Other investigations, which involved various physical or pharmacological 
manipulations, have revealed many situations in which there is no clear relation of atropine-sensitive RSA to arousal or attention. Many treatments which decrease the probability of type 1 movements and produce behavioral states that intuitively seem non-aroused and non-attentive also tend to increase the occurrence of atropinesensitive RSA. After large posterior hypothalamic lesions rats are very akinetic, aphagic, adipsic and show sensory neglect, but also produce long trains of low frequency atropine-sensitive $\mathrm{RSA}^{85,118}$. Although rats do not normally produce atropine-sensitive RSA spontaneously, after treatment with large doses of neuroleptics, such as reserpine, they produce atropine-sensitive RSA both spontaneously and in response to sensory stimulation ${ }^{149}$. Rats, rabbits and cats have all been shown to produce long trains of atropine-sensitive RSA under urethane anesthesia $27,89,149$. Anesthesia with ether or alcohol produces similar effects 143,152 . Therefore, treatments which produce what appear to be, by any common-sense definition, non-aroused or non-attentive states, also increase the occurrence of atropine-sensitive RSA. Of course, these latter results must be interpreted in the context that they involve rather gross alteration of brain function.

The above makes attempts to relate atropine-sensitive RSA to inferred processes in any simple way difficult, and leaves the question as to its functional significance very much unanswered. The fact that sensory stimuli are so potent in producing atropinesensitive RSA, even in anesthetized animals, and that species differ in their response to sensory stimuli, may provide clues for further research as to its functional significance.

The question as to the functional significance of atropine-resistant, movementrelated RSA is not an uncomplicated one either. The finding that atropine-resistant RSA accompanies the performance of one group of behaviors but not another suggests that the ascending inputs which produce this rhythm play a role in, 'the initiation and continued performance of the [type 1] movement' ${ }^{145}$ (p. 23). Some of the differences in the requirements for the production of type 1 versus type 2 movements have been reviewed by Vanderwolf ${ }^{142}$. However, the correlation between RSA and type 1 behaviors does not provide an obvious insight as to the nature of the control these inputs may have over type 1 behaviors, as Vanderwolf readily admits.

The most specific proposal as to the functional significance of atropine-resistant RSA has been forwarded by O'Keefe and Nadal ${ }^{109}$, in context of the 'spatial map' hypothesis of hippocampal function. These researchers note that most of the behaviors accompanied by atropine-resistant RSA are also behaviors involving a displacement of the animal in space. They postulate that the RSA mechanism provides information as to the animals movements in space shifting, 'the focus of excitation from the place representation corresponding to the animals position at the start of the movement to one whose coordinates fit the distance covered by that movement ${ }^{1} 109$ (p. 190). The fact that there is, 'monotonic relationship between the frequency of theta and the distance covered during a jump' is good support for this idea ${ }^{109}$ (p. 224). However, there are some problems with this idea since MRSA also occurs during some behaviors that do not involve displacement of the animal in space, and therefore no adjustment to the 'spatial map' is presumably required. For example, hippocampal RSA accompanies lever-pressing in rats ${ }^{51,160}$, and continues to accompany lever-pressing after 2 million 
presses $^{51}$. It has even been suggested that each lever press occurs at a particular phase of the RSA wave and is part of a mechanism for timing motor behavior 38,129 . Also atropine-resistant RSA accompanies struggling during physical restraint. which prevents movement through space.

It is obvious from the above discussion that a definite answer as to the functional significance of either type of RSA still lies some time in the future. What is clear is that hippocampal electrical activity is tightly correlated with moment-to-moment changes in ongoing motor behavior (atropine-resistant RSA). and even atropine-sensitive RSA cannot be easily related to inferred processes. Obviously, this is not to say that the hippocampus is not involved in, for example, learning and memory. Observations on humans with medial temporal lobe damage initially pointed to hippocampal involvement in memory functions ${ }^{103.127}$, although the role of the hippocampus in even the human amnesic syndrome has recently been challenged ${ }^{76}$ (also see ref. 104). What the data from slow wave recording studies do emphasize is that those inclined to postulate theories of hippocampal function must not only account for the effects of hippocampal lesions and the relations of hippocampal unit activity to behavior, but must also explain why the hippocampus is so interested in moment-to-moment changes in motor behavior.

\section{SUMMARY}

The literature concerning the correlates of hippocampal RSA (theta) has seen a wealth of hypotheses generated from seemingly contradictory data. Two possible reasons for this are examined here. (1) An analysis of the maximum published RSA amplitudes in over 70 papers shows that there is enormous variation in how effective various research groups have been in tapping the hippocampal RSA generator zones. It is suggested that this variation is a major source of 'contradictory data'. The enormous variability is probably due to the fact that the laminar structure of the hippocampus, and the location of two seemingly independent $180^{\circ}$ out-of-phase RSA generators, results in very disparate signals being recorded by electrodes of different configurations. Electrodes which are not optimally placed result in records which may provide misinformation as to whether or not the hippocampus is in the RSA 'mode'. The results of studies with less than adequate records must therefore be viewed with great caution. (2) An explanation often evoked to account for much of the controversy is that of species differences. This idea is examined and it is suggested that there are probably not major species differences in that all of the species appropriately examined thus far have neural systems capable of producing both an atropine-sensitive and an atropine-resistant form of RSA. All species (with the exception of primates) also show relations of RSA to ongoing motor behavior. However, there are definitely species differences in the neural mechanisms underlying the production of atropine-sensitive, immobility-related RSA. Although all species appear to be capable of producing immobility-related RSA some do so only rarely (e.g. rats), while others do so frequently, particularly in response to sensory stimulation (e.g. rabbits, cats, guinea pigs). Therefore, the answer to the question as to whether there are species differences 
in the occurrence of RSA may be yes, or no, depending upon how specifically the question is posed.

\section{ACKNOWLEDGEMENTS}

This project was supported by DRDA Grant 136115 from the University of Michigan. The helpful comments of B. H. Bland, B. Kolb, C. H. Vanderwolf, I. Q. Whishaw and the reviewers on an earlier draft are much appreciated. Thanks are also due to ANKHO International Inc., and Elsevier/North-Holland Biomedical Press for permission to reprint Figs. 1 and 2.

\section{REFERENCES}

1 Adey, W. R., The sensorium and the modulation of cerebral states: tonic environmental influences on limbic and related systems, Ann. N.Y. Acad. Sci., 290 (1977) 396-420.

2 Adey, W. R. and Dunlop, C. W., The action of certain cyclohexamines on hippocampal system during approach performance in the cat, J. Pharmacol. exp. Ther., 130 (1960) 418-426.

3 Adey, W. R., Dunlop, C. W. and Hendrix, C. E., Hippocampal slow waves: distribution and phase relationships in the course of approach learning, Arch. Neurol. (Chic.), 3 (1960) 74-90.

4 Adey, W. R., Merrillees, N. C. R. and Sunderland, S., The entorhinal area : behavioral, evoked potential and histological studies of its interrelationships with brain-stem regions, Brain, 79 (1956) 414439.

5 Adey, W. R., Walter, D. O. and Lindsley, D. F., Subthalamic lesions: effects on learned behavior and correlated hippocampal and subcortical slow-wave activity, Arch. Neurol. (Chic.), 6 (1962) 194-207.

6 Anchel, H. and Lindsley, D. B., Differentiation of two reticulo-hypothalamic systems regulating hippocampal activity, Electroenceph. clin. Neurophysiol., 32 (1972) 209-226.

7 Andersen, P., Discussion. In Ciba Foundation Symposium 58: Functions of the Septo-Hippocampal System, Elsevier, Amsterdam, 1978, p. 312.

8 Andersen, P., Bland, B. H., Ganes, T. and Sveen, O., Analysis of rhythmicity of identified hippocampal neurons during theta activity, unpublished manuscript, 1979.

9 Arnolds, D. E. A. T., Lopes da Silva, F. H., Aitink, J. W. and Kamp, A., Hippocampal EEG and behavior in dog. I. Hippocampal EEG correlates of gross motor behavior, Electroenceph. clin. Neurophysiol., 46 (1979) 552-570.

10 Arnolds, D. E. A. T., Lopes da Silva, F. H. Aitink, J. W. and Kamp, A., Hippocampal EEG and behavior in dog. II. Hippocampal EEG correlates with elementary motor acts, Electroenceph. clin. Neurophysiol., 46 (1979) 571-580.

11 Arnolds, D. E. A. T., Lopes da Silva, F. H., Aitink, J. W. and Kamp, A. Hippocampal EEG and behavior in dog. III. Hippocampal EEG correlates of stimulus-response tasks and of sexual behavior, Electroenceph. clin. Neurophysiol., 46 (1979) 581-591.

12 Arnolds, D., Lopes da Silva, F. H., Kamp A. and Aitink, W., Motor acts and firing of reticular neurons correlated with operantly reinforced hippocampus theta shifts, Brain Research, 85 (1975) 194-195.

13 Artemenko, D. O., Role of hippocampal neurons in theta-wave generation, Nierofiziologiya, 4 (1972) 531-539.

14 Bennett, T. L., Evidence against the theory that hippocampal theta is a correlate of voluntary movement, Commun. Behav. Biol., 4 (1969) 165-169.

15 Bennett, T. L., Hippocampal EEG correlates of behavior, Electroenceph. clin. Neurophysiol., 28 (1970) 17-23.

16 Bennett, T. L., The electrical activity of the hippocampus and the process of attention. In R. L. Isaacson and K. Pribram (Eds.), The Hippocampus, Vol. 2, Neurophysiology and Behavior, Plenum, New York, 1975, pp. 71-99.

17 Bennett, T. L. and French, J., Electrical activity of the cat hippocampus during the species-typical 
gape response: evidence against the voluntary movement hypothesis, Behav. Biol., 21 (1977) 432-437.

18 Bennett, T. L., French, J. and Burnett, K. N., Species differences in the behavior correlates of hippocampal RSA. Behav. Biol., 22 (1978) 161-177.

19 Bennett, T. L. and Gottfried, J., Hippocampal theta and response inhibition, Electroenceph. clin. Neurophysiol., 29 (1970) 196-200.

20 Bennett, T. L., Hebert, P. N. and Moss, D. E., Hippocampal theta activity and the attention component of discrimination learning, Behav. Biol., 8 (1973) 173-181.

21 Bennett, T. L., Nunn, P. J. and Inman, D. P., Effects of scopolamine on hippocampal theta and correlated discrimination performance, Physiol. Behav, 7 (1971) 451-454.

22 Black, A. H., Hippocampal electrical activity and behavior. In R. L. Isaacson and K. II. Pribram (Eds.), The Hippocampus, Vol. 2: Neurophysiology and Behavior, Plenum, New York, 1975, pp. $129-167$.

23 Black, A. H. and Young, G. A., Electrical activity of the hippocampus and cortex in dogs operantly trained to move and to hold still, J. comp. physiol. Psychol., 79 (1972) 128-141.

24 Black, A. H., Young, G. A. and Batenchuk, C., Avoidance training of hippocampal theta waves in Flaxedilized dogs and its relation to skeletal movement, $J$. comp. physiol. Psychol, 70 (1970) 15-24.

25 Bland, B. H., Andersen, P. and Ganes, T., Two generators of hippocampal theta activity in rabbits, Brain Research, 94 (1975) 199-218.

26 Bland, B. H., Andersen, P. and Ganes, T., Participation of identified hippocampal neurons in spontaneous and induced theta activity, unpublished manuscript, 1979.

27 Bland, B. H., Sainsbury, R. S. and Creery, B. L., Anatomical correlates of rhythmical slow wave activity (theta) in the hippocampal formation of the cat, Brain Research, 161 (1979) 199-209.

28 Bland, B. H. and Vanderwolf, C. H., Diencephalic and hippocampal mechanisms of motor activity in the rat : effects of posterior hypothalamic stimulation on behavior and hippocampal slow activity, Brain Research, 43 (1972a) 67-88.

29 Bland, B. H. and Vanderwolf, C. H., Electrical stimulation of the hippocampal formation: behavioral and bioelectric effects, Brain Research, 43 (1972b) 89-106.

30 Bland, B. H. and Whishaw, I. Q., Generators and topography of hippocampal theta (RSA) in the anaesthetized and freely moving rat, Brain Research, 118 (1976) 259-280.

31 Bohus, B., Urban, I., van Wimersma, Tj. B. and de Wied, D., Opposite effects of oxytocin and vasopressin on avoidance behavior and hippocampal rhythm in the rat, Neuropharmacology. 17 (1978) $239-247$.

32 Bradley, P. B. and Nicholson, A. N., The effect of some drugs on hippocampal arousal, Electroenceph. clin. Neurophysiol., 14 (1962) 824-834.

33 Brazier, M. A. B., Studies on the EEG activity of limbic structures in man, Electroenceph. clin. Neurophysiol., 25 (1968) 309-318.

34 Brodie, B. B., Kurz, H. and Schanker, L. S. The importance of dissociation constant and lipidsolubility in influencing the passage of drugs into the cerebrospinal fluid, $J$. Pharmacol. exp. Ther., 130 (1960) 20-25.

35 Brown, B. B., Frequency and phase of hippocampal theta activity in the spontaneously behaving cat, Electroenceph. clin. Neurophysiol., 24 (1968) 53-62.

36 Brown, B. B. and Shryne, J. E., Jr., EEG theta activity and fast activity sleep in cats as related to behavioral traits, Neuropsychologia, 2 (1964) 311-326.

37 Brucke, F., Sailer, S. and Stumpf, C., Wechselwirkungen zwischen Physostigmin einerseits und Evipan, Procain, Largactil and Scopolamin andererseits auf die rhinencephale Tatigkeit des Kaninchens, Naunyn-Schmiedberg's Arch. exp. Parh. Pharmak., 232 (1958) 433-441.

38 Buno, W. and Velluti, J. C., Relationships of hippocampal theta cycles with bar pressing during self-stimulation, Physiol. Behav., 19 (1977) 615-621.

39 Coenen, A. M. L., Frequency analysis of rat hippocampal electrical activity, Physiol. Behav., 14 (1975) 391-394.

40 Coleman, J. R. and Lindsley, D. B., Hippocampal electrical correlates of free behavior and behavior induced by stimulation of two hypothalamic-hippocampal systems in the cat, Exp. Neurol., 49 (1975) 506-528.

41 Coleman, J. R. and Lindsley, D. B., Behavioral and hippocampal electrical changes during operant learning in cats and effects of stimulating two hypothalamic-hippocampal systems, Electroenceph. clin. Neurophysiol., 42 (1977) 309-331. 
42 Cooley, R. K. and Vanderwolf, C. H., Construction of wire leads and electrodes for use in slow wave recordings in small animals, Brain Res. Bull., 3 (1978) 175-179.

43 Crowne, D. P. and Radcliffe, D. D., Some characteristics and functional relations of the electrical activity of the primate hippocampus and a hypothesis of hippocampal function. In R. L. Isaacson and K. H. Pribram (Eds.), The Hippocampus, Vol. 2: Neurophysiology and Behavior, Plenum, New York, 1975, pp. 185-206.

44 Dalton, A. J. and Black, A. H., Hippocampal electrical activity during the operant conditioning of movement and refraining from movement, Commun. Behav. Biol., 2 (1968) 267-273.

45 De Ryck, M. and Teitelbaum, P., Neocortical and hippocampal EEG in normal and lateral hypothalamic-damaged rats, Physiol. Behav., 20 (1978) 403-409.

46 Elazar, Z. and Adey, W. R., Spectral analysis of low frequency components in the electrical activity of the hippocampus during learning, Electroenceph. clin. Neurophysiol., 23 (1967) 225-240.

47 Elazar, Z. and Adey, W. R., Electroencephalographic correlates of learning in subcortical and cortical structures, Electroenceph. clin. Neurophysiol., 23 (1967) 306-319.

48 Frederickson, C. J. et al., Hippocampal electrical activity in mice, unpublished manuscript, 1979.

49 Frederickson, C. J., Miczek, K. A., Zurawin, R. A. and Frederickson, M. H., Hippocampal EEG correlates of intraspecies aggressive behavior in the rat, Brain Behav. Evol, 14 (1977) 352-367.

50 Frederickson, C. J., Smylie, C. S., Howell, G. A. and Lenig, R. B., Movement-dependent and movement-independent changes in hippocampal RSA in cats, Brain Res. Bull, 3 (1978) 559-562.

51 Frederickson, C. J. and Whishaw, I. Q., Hippocampal EEG during learned and unlearned behavior in the rat, Physiol. Behav., 18 (1977) 597-603.

52 Freemon, F. R., McNew, J. J. and Adey, W. R., Sleep of unrestrained chimpanzee: cortical and subcortical recordings, Exp. Neurol., 25 (1969) 129-137.

53 Fujita, Y. and Sato, T., Intracellular recordings from hippocampal pyramidal cells in rabbit during theta rhythm activity, J. Neurophysiol., 27 (1964) 1011-1025.

54 Gerbrandt, L. K., Lawrence, J. C., Eckhardt, J. J. and Lloyd, R. L., Origin of the neocortically monitored theta rhythm in the curarized rat, Electroenceph. clin. Neurophysiol, 45 (1978) 454-467.

55 Giaquinto, S., Sleep recordings from limbic structures in man, Confin. neurol. (Basel), 35 (1973) 285-303.

56 Gillespie, L. A., Ontogeny of Hippocampal Electrical Activity and Behavior in Rat, Rabbit and Guinea Pig, Unpublished Ph. D. thesis, University of Western Ontario, London, 1974.

57 Glazer, $\mathrm{H}$., Instrumental response persistence following induction of hippocampal theta frequency during fixed-ratio responding in rats, J. comp. physiol. Psychol., 86 (1974) 1156-1162.

58 Grantyn, A. A., An intracellular study of hippocampal responses to reticular stimulation, Brain Research, 22 (1970) 409-412.

59 Grantyn, A. A. and Grantyn, R., Postsynaptic responses of hippocampal neurons to mesencephalic stimulation: hyperpolarizing potentials, Brain Research, 45 (1972) 87-100.

60 Grastyan, E., Karmos, G., Vereczkey, L. and Kellenyi, L., The hippocampal electrical correlates of the homeostatic regulation of motivation, Electroenceph. clin. Neurophysiol., 21 (1966) 34-53.

61 Grastyan, E., Linak, K., Madarasz, I. and Donhoffer, H., Hippocampal electrical activity during the development of conditioned reflexes, Electroenceph. clin. Neurophysiol., 11 (1959) 409-430.

62 Grastyan, E. and Vereczkei, L., Effects of spatial separation of the conditioned signal from the reinforcement: a demonstration of the conditioned character of the orienting response or the orientational character of conditioning, Behav. Biol., 10 (1974) 121-146.

63 Gray, J. A., Sodium amobarbital, the hippocampal theta thythm and the partial reinforcement extinction effect, Psychol. Rev., 77 (1970) 465-480.

64 Gray, J. A., Medial septal lesions, hippocampal theta rhythm and the control of vibrissal movement in the freely moving rat, Electroenceph. clin. Neurophysiol., 30 (1970) 189-197.

65 Gray, J. A. and Ball, G. G., Frequency-specific relation between hippocampal theta rhythm, behavior and amobarbital action, Science, 168 (1970) 1246-1248.

66 Gray, J. A., Quinteo, L. and Araujo-Silva, M. T., The partial reinforcement extinction effect in rats with medial septal lesions, Physiol. Behav., 8 (1972) 491-496.

67 Green, J. D. and Arduini, A., Hippocampal electrical activity in arousal, J. Neurophysiol., 17 (1954) 533-557.

68 Green, J. D., Maxwell, D. S., Schindler, W. S. and Stumpf, C., Rabbit EEG 'theta rhythm': its anatomical source and relation to activity in single neurons, $J$ Neurophysiol., 23 (1960) 403-420.

69 Green, J. D. and Petsche, H., Hippocampal electrical activity. II. Virtual generators, Flectroenceph. clin. Neurophysiol., 13 (1961) 847-853. 
70 Guyenet, P., Lefresne, P., Rossier, J., Beaujouan, J.-C. and Glowinski, J., Effect of sodium, hemicholinium-3 and antiparkinson drugs on $\left[{ }^{14} \mathrm{C}\right]$ acetylcholine synthesis and $\left[{ }^{3} \mathrm{H}\right] \mathrm{choline}$ uptake in rat striatal synaptosomes, Brain Research, 62 (1973) 523-529.

71 Halgren, E., Babh, T. L. and Crandall, P. H., Human hippocampal formation FF. I desynchronizes during attentiveness and movement, Electroenceph. clin. Neurophysiol, 44 (1978) 778-781.

72 Harper, R. M., Frequency changes in hippocampal electrical activity during movement and tonic immobility, Physiol. Behav., 7 (1971) 55-58.

73 Heath, R. G., Physiologic basis of emotional expression: evoked potential and mirror focus studies in rhesus monkeys, Biol. Psychiat., 5 (1972) 15-31.

74 Herz, A., Teschemacher, H., Hofstetter, A. and Kurz, H., The importance of lipid-solubility for the central action of cholinolytic drugs, Int. $J$. Neuropharmacol, 4 (1965) $207-218$.

75 Holmes, J. E. and Adey, W. R., The electrical activity of the entorhinal cortex during conditioned behavior, Amer. J. Physiol., 199 (1960) $741-744$.

76 Horel, J. A., The neuroanatomy of amnesta. A critique of the hippocampal memory hypothesis, Brain, 101 (1978) 403-445.

77 Irmis, F., Lat, J. and Radil-Weiss, T., Individual differences in hippccampal EEG during rhomencephalic sleep and arousal, Physiol. Behav., 7 (1971) 117-119.

78 Irmis, F., Madlafousek, J., and Hlinak, Z, Hippocampal electrical activity in course of sexual behavior of male rats, Physiol. bohemoslov., 19 (1970b) 83-87.

79 Irmis, F., Radil-Weiss, T., Lat, J. and Krekule, I., Inter-individual differences in hippocampal theta activity during habituation, Electroenceph. clin. Neurophysiol., 28 (1970a) 24-31.

80 James, D. T. D., McNaughton, N., Rawlins, J. N. P., Feldon, J. and Gray, J. A., Septal driving of hippocampal theta rhythm as a function of frequency in the free-moving male rat, Neuroscience, 2 (1977) 1007-1017.

81 Kamp, A., Lopes da Silva, F. H. and Storm van Leeuwen, W., Hippocampal frequency shifts in different behavioral situations, Brain Research, 31 (1971) 287-294.

82 Kemp, 1. R. and Kaada, B., The relation of hippocampal theta activity to arousal, attentive behavior and somato-motor movements in unrestrained cats, Brain Research, 95 (1975) 323-342.

83 Klemm, W. R., Correlation of hippocampal theta rhythm, muscle activity and brain stem reticular formation activity, Commun. Behav. Biol., 5 (1970) 147-151.

$84 \mathrm{Klemm}$, W. R., EEG and multiple-unit activity in limbic and motor systems during movement and immobility, Physiol. Behav., 7 (1971) 337-343.

$85 \mathrm{Kolb}, \mathrm{B}$. and Whishaw, 1. Q., Effects of brain lesions and atropine on hippocampal and neocortical EEG in the rat, Exp. Neurol. 56 (1977) 1-22.

86 Komisaruk, B., Synchrony between limbic system theta activity and rhythmical behavior in rats, J. comp physial. Psychol., 70 (1970) 482-492.

87 Konorski, J., Santibaniz, H. G. and Beck, J., Electrical hippocampal activity and heart rate in classical and instrumental conditioning, Acta biol. exp., 28 (1968) 169-185.

88 Kramis, R. C. and Routtenberg, A., Rewarding brain stimulation, hippocampal activity, and footstomping in the gerbil, Physiol, Behav, 4 (1969) 7-11.

89 Kramis, R., Vanderwolf, C. H. and Bland, B. H., Two lypes of hippocampal rhythmical slow activity in both the rabbit and the rat: relations to behavior and effects of atropine, diethyl ether, urethane, and pentobarbital, Exp. Neurol., 49 (1975) 58-85.

$90 \mathrm{Kurtz}, \mathrm{R}$. G., Hippocampal and cortical activity during sexual behavior in the female rat, J. comp. physiol. Psychol., 89 (1975) $158-169$.

91 Kurtz, R. G. and Adler, N. T., Electrophysiological correlates of copulatory behavior in the male rat: evidence for a sexual inhibitory process, $J$. comp. physiol. Psychol., 84 (1973) 225 239.

92 Landfield, P. W., Computer-determined EEG patterns associated with memory-facilitating drug; and with ECS, Brain Res. Bull., 1 (1976) 9-17.

93 Landfield, P. W., Synchronous EEG rhythms : their nature and their possible functions in memory, information transmission and behavior. In W. H. Gispen (Ed.), Molecular and Functional Neurobiology, Elsevier, Amsterdam, 1976, pp. 389-424.

94 Landfield, P. W., Different effects of post-trial driving or blocking of the theta rhythm on avoidance learning in rats, Physiol. Behav., 18 (1977) $439-445$.

95 Landfield, P. W. and McGaugh, J. L., Effects of electroconvulsive shock and brain stimulation on EEG cortical theta rhythms in rats, Behav. Biol., 7 (1972) 271-278.

96 Landfield, P. W., McGaugh, J. L. and Tusa, R. J., Theta rhythm: a temporal correlate of memory storage processes in the rat, Science, 175 (1972) 87-89. 
97 LeMoal, M. and Cardo, B., Rhythmic slow wave activity recorded in the ventral mesencephalic tegmentum in the rat, Electroenceph. clin. Neurophysiol., 38 (1975) 139-147.

98 Lena, C. and Parmeggiani, P. L.. Hippocampal theta rhythm and activated sleep, Helv. physiol. Acta, 22 (1964) 120-135.

99 Lindsley, D. B. and Wilson, C. L,, Brain stem-hypothalamic systems influencing hippocampal activity and behavior. In R. L. Isaacson and K. H. Pribram (Eds.), The Hippocampus, Vol. 2, Neurophysiology and Behavior, Plenum, New York, 1975, pp. 247-278.

100 Lopes da Silva, F. H. and Kamp, A., Hippocampal theta frequency shifts and operant behavior, Electroenceph. clin. Neurophysiol., 27 (1969) 133-143.

101 Macadar, A. W., Chalupa, L. M. and Lindsley, D. B., Differentiation of brain stem loci which affect hippocampal and neocortical electrical activity, Exp. Neurol., 43 (1974) 499-514.

102 McGowan-Sass, B. K., Differentiation of electrical rhythms and functional specificity of the hippocampus of the rat, Physiol. Behav., 11 (1973) 187-194.

103 Milner, B., Hemispheric specialization: scope and limits. In F. O. Schmitt and F. G. Worden (Eds.), The Neurosciences: Third Study Program, MIT Press, Cambridge, 1974 pp. 75-89.

104 Mishkin, M., Memory in monkeys severely impaired by combined but not by separate removal of amygdala and hippocampus, Nature (Lond.), 273 (1978) 297-298.

105 Moise, S. L., Jr. and Costin, A., Hippocampal, hypothalamic and lateral geniculate activity during visual discrimination in the monkey, Physiol. Behav., 12 (1974) 835-841.

106 Morris, R. G. M. and Black, A. H., Hippocampal electrical activity and behavior elicited by nonreward, Behav. Biol., 22 (1978) 524-532.

107 Nakahara, D., Yukie, M. and Iwahara, S., Effects of atropine sulphate upon hippocampal theta activity and eye movements during different behavioral states of cats, Jap. psychol. Res., 19 (1977) 9-15.

$1080^{\circ}$ Keefe, J., Place units in the hippocampus of the freely moving rat, Exp. Neurol., 51 (1976) 78-109.

109 O'Keefe, J. and Nadal, L., The Hippocampus as a Cognitive Map, Oxford University Press, Oxford, 1978.

110 Olmstead, C. E. and Villablanca, J. R., Hippocampal theta rhythm persists in the permanently isolated forebrain of the cat, Brain Res. Bull., 2 (1977) 93-100.

111 Petsche, H. and Stumpf, Ch., Topographic and toposcopic study of origin and spread of the reticular synchronized arousal pattern in the rabbit, Electroenceph. clin. Neurophysiol., 12 (1960) 589-600.

112 Pickenhain, L. and Klingberg, F., Hippocampal slow wave activity as a correlate of basic behavioral mechanisms in the rat. In W. R. Adey and T. Tokizane (Eds.), Structure and Funcrion of the Limbic System, Progress in Brain Research, Vol. 27, Elsevier, Amsterdam, 1967, pp. 218-227.

113 Radulovacki, M. and Adey, W. R., The hippocampus and the orienting response, Exp. Neurol. 12 (1965) 68-83.

114 Ranck, J. B., Jr., Studies on single neurons in dorsal hippocampal formation and septum in unrestrained rats. Part 1., Behavioral correlates and firing repertoires, Exp. Neurol., 41 (1973) $462-531$.

115 Robinson, T. E., Kramis, R. C. and Vanderwolf, C. H., Two types of cerebral activation during active sleep: relations to behavior, Brain Research, 124 (1977) 544-549.

116 Robinson, T. E. and Vanderwolf, C. H., Electrical stimulation of the brain stem in freely moving rats: effects on hippocampal and neocortical elcctrical activity, and relations to tehavior, Exp. Neurol., 61 (1978) 485-515.

117 Robinson, T. E., Vanderwolf, C. H. and Pappas, B. A., Are the dorsal noradrenergic bundle projections from the locus coeruleus important for neocortical or hippocampal activation? Brain Research, 138 (1977) 75-98,

118 Robinson, T. E. and Whishaw, I. Q., Effects of posterior hypothalamic lesions on voluntary tehavior and hippocampal electroencephalograms in the rat. J. comp. physiol. Psychol., 86 (1974) 768-786.

119 Rommelspacher, H. and Kuhar, M. J. Effects of electrical stimulation on acetylcholine levels in central cholinergic nerve terminals, Brain Research, 81 (1974) 243-251.

120 Routtenberg, A., Hippocampal correlates of consummatory and obscrved behavior, Physiol. Behav., 3 (1968) 533-536.

121 Routtenberg, A. and Kramis, R. C., Hippocampal correlates of aversive midbrain stimulation, Science, 160 (1968) 1363-1365.

122 Routtenberg, A. and Taub, F., Hippocampus and superior colliculus: congruent EEG activity demonstrated by a simple measure, Behav. Biol., 8 (1973) 801-805. 
123 Sainsbury, R. S., Hippocampal activity during natural behavior in the guinea pig, Physiol. Behav., $5(1970) 317-324$.

124 Sakai, K., Sano, K. and Iwahara, S., Eye movements and hippocampal theta activity in cats, Electroenceph. clin. Neurophysiol., 34 (1973) 547-549.

125 Sano, K., Iwahara, S., Semba, K., Sano, A. and Yamazaki, S., Eye movements and hippocampal theta activity in rats, Electroenceph. clin. Neurophysiol., 35 (1973) 621-625.

126 Sano, K., Mayanagi, Y., Sekino, H., Ogashiwa, M. and Ishijima, B., Results of stimulation and destruction of the posterior hypothalamus in man, $J$. Neurosurg., 33 (1970) 689-707.

127 Scoville, W. B, and Milner, B., Loss of recent memory after bilateral hippccampal lesions, $J$. Neurol, 20 (1957) 11-19.

128 Segal, M., A correlation between hippocampal responses to interhemispheric stimulation, hippocampal slow rhythmic activity and behavior, Electroenceph. clin. Neurophysiol., 45 (1978) 409 411.

129 Semba, K. and Komisaruk, B. R., Phase of the theta wave in relation to different limb movements in awake rats, Electroenceph. clin. Neurophysiol., 44 (1978) 61-71.

130 Smylie, C. S., Lenig, R. B. and Frederickson, C. H., Effects of scopolamine and atropine on hippocampal EEG in the cat, Neurosci. Abstr., 3 (1977) 206.

131 Soulairac, A., Gottesmann, C. et Thangapregassam, J., Etude electrophysiologique des differentes phases de sommeil chez le rat, Arch. ital, Biol., 103 (1965) 469-482.

132 Storm van Leeuwen, W., Kamp, A., Kok, M. L., De Quartel, F., Lopes da Silva, F. H. et Tielen, A. M., Relations entre les activites electriques cerebrales du chien, son comportement et sa direction d'attention, Act. Neurophysiol., 7 (1967) 167-186.

133 Teitelbaum, H., Lee, J. F. and Johannessen, J. N., Behaviorally evoked hippocampal theta waves: a cholinergic response, Science, 188 (1975) 1114-1116.

134 Teitelbaum, H. and McFarland, W. L., Power spectral shifts in hippocampal EEG associated with conditioned locomotion in the rat, Physiol. Behav., 7 (1971) 545-549.

135 Teitelbaum, H., McFarland, W. L. and Mattsson, J. L. ,Classical conditioning of hippocampal theta patterns in the rat, J. comp. physiol. Psychol., 91 (1977) 674-681.

136 Tonnesen, M., The absorption and distribution of atropine in rats, Acta pharmacol. (Kbh.), 4 (1948) 367-378.

137 Urban, I. and De Wied, D., Inferior quality of RSA during paradoxical sleep in rats with hereditary diabetes insipidus, Brain Research, 97 (1975) 362-366.

138 Urban, I. and De Wied, D., Changes in excitability of the theta activity generating substrate oy ACTH-4-10 in the rat, Exp. Brain Res., 24 (1976) 325-334.

139 Urban, 1. and De Wied, D., Neuropeptides : effects on paradoxical sleep and theta rhythm in rats, Pharmacol. Biochem. Behav, 8 (1978) 51-59.

140 Usui, S. and I wahara, S., Effects of atropine upon the hippocampal electrical activity in rats with special reference to paradoxical sleep, Electroenceph. clin. Neurophysiol., 42 (1977) 510-517.

141 Vanderwolf, C. H., Hippocampal electrical activity and voluntary movement in the rat, Electroenceph. clin. Neurophysiol, 27 (1969) 407-418.

142 Vanderwolf, C. H., Limbic-diencephalic mechanisms of voluntary movement, Psychol. Rev., 78 (1971) 83-113.

143 Vanderwolf, C. H., Neocortical and hippocampal activation in relation to behavior: effects of atropine, eserine, phenothiazines and amphetamine, J. comp. physiol. Psychol., 88 (1975) 300-323.

144 Vanderwolf, C. H., Hippocampal activity and scopolamine, Science, 192 (1976) 914.

145 Vanderwolf, $C$. H., The role of the cerebral cortex and ascending activating systems in the control of behavior. In E. Satinoff and P. Teitelbaum (Eds.), Handbook of Behavioral Neurobiology, Plenum, New York, 1979, in press.

146 Vanderwolf, C. H., Bland, B. H. and Whishaw, 1. Q., Diencephalic, hippocampal and neocortical mechanisms in voluntary movement. In J. D. Maser (Ed.), Efferent Organization and the Integrc. tion of Behavior, Academic Press, New York, 1973, pp. 229-262.

147 Vanderwolf, C. H. and Cooley, R. K., Hippocampal electrical activity during long-continued avoidance performance: effects of fatigue, Physiol. Behav., 13 (1974) 819-823.

148 Vanderwolf, C. H., Kramis, R. Gillespie, L. A. and Bland, B. H., Hippocampal rhythmical slow activity and neocortical low voltage fast activity: relations to behavior. In R. L. Isaacson and K. H. Pribram (Eds.), The Hippocampus, Vol. 2: Neurophysiology and Behavior, Plenum, New York, 1975, pp. 101-128.

149 Vanderwolf, C. H., Kramis, R. C. and Robinson, T. E., Hippocampal electrical activity during waking behavior and sleep: analyses using centrally acting drugs. In Ciba Foundation Symposium 58: Functions of the Septo-Hippocampal System, Elsevier, Amsterdam, 1978, pp. 199-221. 
150 Vertes, R. P., Brain stem gigantocellular neurons: patterns of activity during behavior and sleep in the freely moving rat, $J$. Neurophysiol., 42 (1979) 214-228.

151 Whishaw, 1. Q., Hippocampal electroencephalographic activity in the Mongolian gerbil during natural behaviors and wheel running and in the rat during wheel running and conditioned immobility, Canad. J. Psychol., 26 (1972) 219-239.

152 Whishaw, 1. Q., The effects of alcohol and atropine on EEG and behavior in the rabbit, Psychopharmacology, 48 (1976) 83-90.

153 Whishaw, 1. Q., Bland, B. H. and Bayer, S. A., Postnatal hippocampal granule cell agenesis in the rat: effects on two types of rhythmical slow activity (RSA) in two hippocampal generators, Brain Research, 146 (1978) 249-268.

154 Whishaw, I. Q., Bland, B, H., Robinson, T. E. and Vanderwolf, C. H., Neuromuscular blockade: the effects on two hippocampal RSA (theta) systems and neocortical desynchronization, Brain Res. Bull., 1 (1976) 573-581.

155 Whishaw, I. Q., Bland, B. H. and Vanderwolf, C. H., Hippocampal activity, behavior, self-stimulation, and heart rate during electrical stimulation of the lateral hypothalamus, $J$. comp, physiol. Psychol., 79 (1972) 115-127.

156 Whishaw, I. Q. and Nikkel, R. W., Anterior hypothalamic electrical stimulation and hippocampal EEG in the rat. Suppressed EEG, locomotion, self-stimulation and inhibition of shock avoidance, Behav. Biol.. 13 (1975) 1-20.

157 Whishaw, I. Q., Robinson, T. E. and Schallert, T., Intraventricular anticholinergics do not block cholinergic hippocampal RSA or neocortical desynchronization in the rabbit or rat, Pharmacol. Biochem. Behav., 5 (1976) 275-283.

158 Whishaw, I. Q. and Schallert, T., Hippocampal RSA (theta), apnea, bradycardia and effects of atropine during underwater swimming in the rat, Electroenceph. clin. Neurophysiol., 42 (1977) 389-396.

159 Whishaw, I. Q. and Vanderwolf, C. H., Hippocampal EEG and behavior: effects of variation in body temperature and relation of EEG to vibrissae movement, swimming and shivering, Physiol. Behav., 6 (1971) 391-397.

160 Whishaw, I. Q. and Vanderwolf, C. H., Hippocampal EEG and behavior: changes in amplitude and frequency of RSA (theta rhythm) associated with spontaneous and learned movement patterns in rats and cats, Behav. Biol., 8 (1973) $461-484$.

161 Winson, J., Interspecies differences in the occurrence of theta, Behav. Biol., 7 (1972) 479-487.

162 Winson, J., Patterns of hippocampal theta rhythm in the freely moving rat, Electroenceph. clin. Neurophysiol., 37 (1974) 291-301.

163 Winson, J., The $\theta$ mode of hippocampal function. In R. L. Isaacson and K. H. Pribram (Eds.), The Hippocampus, Vol. 2: Neurophysiology and Behavior, Plenum, New York, 1975, pp. 169-183.

164 Winson, J., Hippocampal theta rhythm. I. Depth profiles in the curarized rat, Brain Research, 103 (1976) $57-70$.

165 Winson, J., Hippocampal theta rhythm. II. Depth profiles in the freely moving rabbit, Brain Research, 103 (1976) 71-79.

166 Yamaguchi, Y., Yoshii, N., Miyamoto, K. and Itoigawa, N., A study on the invasive hippocampal $\theta$-waves to the cortex. In W. R. Adey and T. Tokizane (Eds.), Structure and Function of the Limbic System, Progress in Brain Res., Vol. 27, Elsevier, Amsterdam, 1967, pp. 353-375.

167 Yoshii, N., Shimakochi, M., Miyamoto, K. and Ito, M., Studies on the neuronal basis of behavior by continuous frequency analysis of EEG, In T. Tokizane and J. P. Schade (Eds.), Correlative Neurosciences, Progress in Brain Research, Vol. 21A, Elsevier, Amsterdam, 1966, pp. 217-250.

168 Young, G. A., Electrical activity of the dorsal hippocampus in rats operantly trained to lever press and to lick, J. comp. physiol. Psychol., 90 (1976) 78-90. 